This document represents the final manuscript submitted prior to publication. Please cite the published work:

O. L. G. Alderman, A. C. Hannon, D. Holland, S. Feller, G. Lehr, A. J. Vitale, U. Hoppe, M. v Zimmermann, A. Watenphul, Phys. Chem. Chem. Phys., 2013, 15, 8506-8519, DOI: 10.1039/С3CP51348C 


\title{
Lone-Pair Distribution and Plumbite Network Formation in High Lead Silicate Glass, $80 \mathrm{PbO} .20 \mathrm{SiO}_{2}+$
}

\author{
Oliver L. G. Alderman, ${ }^{a}$ Alex C. Hannon, ${ }^{b}$ Diane Holland, ${ }^{a}$ Steve Feller, ${ }^{c}$ Gloria \\ Lehr, ${ }^{c}$ Adam Vitale, ${ }^{c}$ Uwe Hoppe, ${ }^{d}$ Martin v. Zimmerman, ${ }^{\mathrm{e}}$ Anke Watenphul ${ }^{\mathrm{e}}$ \\ a. Department of Physics, University of Warwick, CV4 7AL, UK \\ b. ISIS Facility, Rutherford Appleton Laboratory, Chilton, Didcot, Oxon OX11 0QX, UK \\ c. Physics Department, Coe College, Cedar Rapids, IA 52402, USA \\ d. Institut für Physik, Universität Rostock, 18051 Rostock, Germany \\ e. Deutsches Elektronen-Synchrotron DESY, Notkestrasse 85, D-22603 Hamburg, Germany
}

\begin{abstract}
For the first time a detailed structural model has been determined which shows how the lone-pairs of electrons are arranged relative to each other in a glass network containing lone-pair cations. High energy $\mathrm{x}$-ray and neutron diffraction patterns of a very high lead content silicate glass

$\left(80 \mathrm{PbO} .20 \mathrm{SiO}_{2}\right)$ have been used to build three-dimensional models using empirical potential structure refinement. Coordination number and bond angle distributions reveal structural similarity

to crystalline $\mathrm{Pb}_{11} \mathrm{Si}_{3} \mathrm{O}_{17}$ and $\alpha$ - and $\beta$ - $\mathrm{PbO}$, and therefore strong evidence for a plumbite glass network built from pyramidal $\left[\mathrm{PbO}_{m}\right]$ polyhedra $\left(m^{\sim 3}-4\right)$, with stereochemically active lone-pairs,

although with greater disorder in the first coordination shell of lead compared to the first coordination shell of silicon. The oxygen atoms are coordinated predominantly to four cations. Explicit introduction of lone-pair entities into some models leads to modification of the local $\mathrm{Pb}$ environment, whilst still allowing for reproduction of the measured diffraction patterns, thus demonstrating the non-uniqueness of the solutions. Nonetheless, the models share many features with crystalline $\mathrm{Pb}_{11} \mathrm{Si}_{3} \mathrm{O}_{17}$, including the $\mathrm{O}-\mathrm{Pb}-\mathrm{O}$ bond angle distribution, which is more highly structured than reported for lower $\mathrm{Pb}$ content glasses using reverse Monte Carlo techniques. The lone-pair separation of $2.85 \AA$ in the model glasses compares favourably with that estimated in $\alpha$ $\mathrm{PbO}$ as $2.88 \AA$, and these lone-pairs organise to create voids in the glass, just as they create channels in $\mathrm{Pb}_{11} \mathrm{Si}_{3} \mathrm{O}_{17}$ and interlayer spaces in the $\mathrm{PbO}$ polymorphs.
\end{abstract}

\footnotetext{
† Electronic supplementary information (ESI) available: Full experimental details: X-ray diffraction; Neutron diffraction; EDX measurements. Total scattering formalism. Neutron and x-ray diffraction from a vitreous $\mathrm{SiO}_{2}$ standard. Additional EPSR modelling results: Partial pair interference functions; Low $Q$ neutron and $x$-ray distinct scattering functions; coordination number histograms; Oxygen speciation within $\mathrm{Pb}_{11} \mathrm{Si}_{3} \mathrm{O}_{17}$. Linking the silicate $\mathrm{Q}^{\mathrm{n}}$ speciation to the fraction of plumbite oxygen. X-ray differential correlation function.
} 


\section{Introduction}

A clear picture of the role of lone-pairs (LPS) of electrons in a glass is important for an understanding of non-linear optical (NLO) properties, ${ }^{1-2}$ and their location in the network is of interest from a fundamental structural point of view. ${ }^{3}$ However, the location of LPs in a structure cannot be measured directly, but has to be derived indirectly from other structural information. Therefore it is necessary to build up a comprehensive model of the structure of a material in order to infer the location of the LPs, and this is what we have done for a lead silicate glass with an extremely high lead content.

The results from numerous studies (using diffraction, ${ }^{4-15} \mathrm{~Pb} \mathrm{~L}_{\text {III }}$ edge EXAFS, ${ }^{16-18} \mathrm{ESR}^{19}{ }^{19} \mathrm{Si}$ MAS $\mathrm{NMR}^{14,}{ }^{140-23}{ }^{207} \mathrm{~Pb}$ NMR, ${ }^{16,22,24-25} \mathrm{XPS}^{26-29}$ vibrational spectroscopy ${ }^{23,30-34}$ and molecular dynamics ${ }^{18,35-}$ ${ }^{41}$ ) show that most, if not all, $\mathrm{Pb}^{2+}$ cations in lead silicate glasses exist in environments similar to those found in the known crystalline silicates ${ }^{42-47}$ and monoxides ${ }^{48-49}$ of lead. That is, they have an occupied non-bonding or LP orbital, and a low coordination number of three or four oxygens distributed anisotropically about the lead cation. Such low coordination to oxygen is associated with a larger degree of covalency in the $\mathrm{Pb}-\mathrm{O}$ bonds and these types of $\left[\mathrm{PbO}_{m}\right]$ units $\left(m^{\sim 3}-4\right)$ are conducive to the formation of a glass network. ${ }^{50}$

Rapid twin-roller quenching has recently been used to prepare lead silicate glasses with up to $83 \mathrm{~mol} \% \mathrm{PbO}^{23}$ which is well beyond the conventional glass-forming limit of $67 \mathrm{~mol} \% \mathrm{PbO}$, at which the silicate network is completely depolymerised into monomeric $\mathrm{Q}^{0}$ species ([ $\left.\mathrm{SiO}_{4}\right]^{4-}$ anions). For lead silicate glasses to form beyond this limit, there must be a $\mathrm{Pb}-\mathrm{O}$ based plumbite subnetwork containing 'plumbite' oxygen atoms bonded only to $\mathrm{Pb}^{2+}$, and $\mathrm{PbO}$ is therefore considered as an intermediate oxide, between glass-modifying and glass-forming oxides. ${ }^{51}$ There is evidence from both $\mathrm{x}$-ray photoelectron ${ }^{28-29}$ (XPS) and ${ }^{29} \mathrm{Si}$ MAS NMR ${ }^{22-23}$ spectroscopies that plumbite oxygens exist in lead silicate glasses from as little as 50 mol\% PbO.

The occurrence of glasses with $\mathrm{PbO}$ contents beyond the conventional glass-forming limit raises the important fundamental structural question of how the $\left[\mathrm{PbO}_{m}\right]$ polyhedra connect together to form the plumbite subnetwork, and in particular how the LPs are arranged; simplistically one might expect an avoidance of close proximity between these centres of negative charge. On the basis of a Reverse Monte Carlo (RMC) simulation of $\mathrm{x}$-ray and neutron diffraction data for lead silicate glasses containing 34, 50 and 65 mol\% $\mathrm{PbO}, 12,15$ it has recently been concluded that lead silicate glasses contain a large amount of 'free volume', in comparison to sodium or calcium silicate glasses. However, the role of the stereochemically active electron lone-pairs on the $\mathrm{Pb}^{2+}$ ions, particularly in relation to the free volume, was not considered. A different structural model for lead silicate glasses has been proposed by Takaishi et al., ${ }^{14}$ in which the $\mathrm{Pb}$ cations are present predominantly as $\mathrm{PbO}_{3}$ trigonal pyramids, which are interconnected by edges to form $\mathrm{Pb}_{2} \mathrm{O}_{4}$ moieties, and have opposed orientations arising from steric repulsion between their respective electron lone-pairs. Whether or not a three-dimensional space-filling model, with the correct atomic number density, can be constructed based on such motifs was not addressed.

Diffraction is a key experimental technique for the investigation of glass structure, ${ }^{52}$ but leadcontaining glass presents particular difficulty due to the very high absorption of $x$-rays by $\mathrm{Pb}$. This difficulty may be overcome by performing $x$-ray diffraction using high energy $x$-rays at a synchrotron 
source, but the results are very strongly dominated by the contribution from the $\mathrm{Pb}$. Thus an investigation of lead silicate glasses by $x$-ray diffraction alone is rather insensitive to oxygen and to the silicate part of the network. On the other hand, neutron diffraction is much more sensitive to oxygen in particular, and hence a combined study using both high energy $x$-ray diffraction and neutron diffraction is much more informative about the detailed glass structure.

In contrast to perfect crystals, no unique solution exists for the structure of an amorphous material, and hence modelling techniques are required to characterise the structure. For example, classical molecular dynamics (MD) has been used to predict the structure of lead silicate glasses. ${ }^{18,35-41}$ However, all of the interatomic potentials employed are inappropriate for the treatment of the highly polarisable $\mathrm{Pb}^{2+}$ cation, which interacts anisotropically if the electron lone-pair has $p$-character and is stereochemically active. ${ }^{35}$ An alternative to structure prediction by MD is to use an empirical approach, such as $\mathrm{RMC}^{53}$ in which the atoms in a model are moved so as to optimise the agreement with experimental diffraction data. A difficulty of the RMC method is that the simulation results depend on the initial model, so that the final structure is essentially a refinement of the original configuration and still has many of the same topological properties. ${ }^{54}$ Instead we have used the related technique of empirical potential structure refinement (EPSR) to investigate the local geometrical arrangement of oxygen about $\mathrm{Pb}^{2+}$ cations, and also the way in which the $\left[\mathrm{PbO}_{m}\right]$ polyhedra interconnect and the corresponding disposition of the electron LPs. In the EPSR approach, the potential between the atoms in the model is adjusted to optimise the agreement with diffraction data, ${ }^{55}$ and hence the structural model obtained is less dependent on the assumptions used to form the initial model.

Pure lead monoxide glass has never been obtained, but binary oxide glasses, with general formula $x \mathrm{PbO}$.(100 - $x) \mathrm{M}_{a} \mathrm{O}_{b}$, can be obtained over wide ranges of $\mathrm{PbO}$ concentration. Heavy-metal oxide $(\mathrm{HMO})$ glasses $^{1}$ include those with $>50$ cation $\% \mathrm{~Pb}$ and have wide ranging technological applications. For example $\mathrm{HMO}$ glasses are typified by large infrared transmission windows, low working and glass transformation temperatures, and high refractive indices and higher order electric susceptibilities due to the large polarisabilities and hyperpolarisabilities of heavy-metal cations. Hence HMO glasses find application as low loss fibres, glass solders, and NLO materials, as well as radiation shields and hosts for scintillating inclusions. ${ }^{1}$ We report a combined high energy $x$-ray diffraction and neutron diffraction study of the structure of a glass of composition $80 \mathrm{PbO}^{2} 20 \mathrm{SiO}_{2}$, made by rapid twin-roller quenching. ${ }^{56}$ This composition is chosen to be near to the high $\mathrm{PbO}$ limit for glass formation by this method, and the results obtained are complementary to the multispectroscopic results obtained by Feller et al. ${ }^{23}$ for lead silicate glasses with a wide range of composition, which are sensitive to the silicate subnetwork, but do not provide information on the disposition of the LPs.

\section{Experimental}

\section{Glass Preparation and Characterisation}

Powders of $\mathrm{PbO}$ (Aldrich, 99.9+ \%) and $\mathrm{SiO}_{2}$ (Aldrich, 99.6\%) were mixed in quantities to yield $10 \mathrm{~g}$ batches of glass with a $\mathrm{PbO}: \mathrm{SiO}_{2}$ molar ratio of 4:1. The mixtures were placed in pure platinum crucibles in an electric furnace held at $1000^{\circ} \mathrm{C}$ for 20 minutes. After this period, the mass loss was recorded and the crucibles replaced into the furnace for an additional 10 minutes. The liquids were 
vitrified using rapid twin-roller quenching (estimated cooling rate $\sim 10^{5} \mathrm{~K} / \mathrm{s}$ ). ${ }^{57}$ The resultant flakes of translucent glass were yellow-gold in colour.

Density measurements (Table 1) were made using helium gas in a Quantachrome Micropycnometer and glass composition was measured using energy dispersive $x$-ray spectroscopy (EDX) in a Zeiss SUPRA 55-VP FEG SEM operating at an accelerating voltage of $20 \mathrm{kV}$. Glass composition was estimated in several additional ways (Table 1): i) from $\mathrm{PbO}$ mass loss during melting, ii) by extrapolating from literature density values, ${ }^{58-59} \mathrm{iii)}$ by requiring that the Si-O coordination number measured by neutron diffraction (ND) be $3.96 \pm 0.05$, in accord with the value measured for vitreous silica (see ESI). All methods indicate a slightly lower $\mathrm{PbO}$ content than nominal, likely due to volatilisation of $\mathrm{PbO}$ from the melt. The ND derived glass composition of $79.5 \pm 0.5 \mathrm{~mol} \% \mathrm{PbO}$ will be used in all subsequent analyses. EDX also ruled out significant levels ( $>0.5$ at.\%) of impurity.

\section{X-ray Diffraction}

Wiggler beamline $B W 5^{60}$ on the synchrotron radiation source DORIS III, HASYLAB at DESY, was used for an x-ray diffraction measurement of the powdered glass, which was held inside a $1.5 \mathrm{~mm}$ diameter silica glass capillary ( $20 \mu \mathrm{m}$ wall thickness). Measurements of an empty capillary and the empty instrument were made to allow removal of background scattering. The x-ray energy of $84.768 \mathrm{keV}$ (wavelength $0.14626 \AA$ ), was optimised so as to minimise the photoelectric absorption cross-section whilst avoiding fluorescence associated with the Pb K-edge at $88.0045 \mathrm{keV}{ }^{61}$ Use of such high energy $\mathrm{x}$-rays also makes accessible a large maximum scattering vector magnitude, $Q_{\max }=23.62 \AA^{-1}$, at the maximum scattering angle of $32.0^{\circ}$. Data were collected in three angular ranges using different attenuators between sample and detector, owing to the form factor dependence of $x$-ray signal, and to ensure that the count rate in the Ge detector did not greatly exceed $5 \times 10^{4}$ counts per second. All sets of data were combined after omission of bad points, dead-time correction, normalisation to the incident beam monitor counts, correction for the geometrical arrangement of the detector and sample and scaling as required for datasets for which different levels of in-beam attenuation were used. A very small irregularity in the diffraction pattern at $3.85 \AA^{-1}$ is attributed to a crystallite, possibly of $\beta-\mathrm{PbO}^{49}$ (the (131) reflection), and was neglected during analysis. A vitreous silica standard was also measured, see ESI.

\section{Neutron Diffraction}

A time-of-flight neutron diffraction measurement was made using the GEM ${ }^{62}$ diffractometer at the ISIS Facility, Rutherford Appleton Laboratory, UK. The glass, in the form of small (few $\mathrm{mm}^{2}$ ) flakes, was loaded into a thin $(25 \mu \mathrm{m})$ walled vanadium can of internal diameter $8.3 \mathrm{~mm}$. Data were collected with sufficient statistics to justify use of a maximum scattering vector magnitude of $Q_{\max }=40.0 \AA^{-1}$ for the Fourier transform. Measurements were also performed on an empty vanadium can, the empty instrument, and an $8.34 \mathrm{~mm}$ diameter vanadium rod for normalisation purposes and to allow for subtraction of background signals. A vitreous silica standard was also measured, see ESI.

\section{Structure Refinement}

Empirical potential structure refinement (EPSR) ${ }^{63}$ is a method for generating physically reasonable atomistic models of condensed amorphous systems which are consistent with total scattering 
measurements. It is related to the $\mathrm{RMC}^{53}$ method, but distinct in that it is based on a Monte Carlo simulation using interatomic pair-potentials, with the constraints from the diffraction data imposed as a perturbation on the starting reference potentials. The various constraints that must be imposed during RMC modelling in order to ensure physically plausible models are therefore naturally included in EPSR by way of the reference potential. Here four different models are derived, using slightly different reference potentials, and will be referred to for simplicity as the: i) ionic model; ii) lone-pair model; iii) $Q^{0}$ model; and iv) $Q^{0}+$ lone-pair model.

All four employ reference potentials consisting of standard Lennard-Jones plus Coulomb terms, but the lone-pair models have the $\mathrm{Pb}$ introduced as pseudomolecular entities (dipoles), as a crude means of representing a stereochemically active $L P$ of electrons on all $P b$ sites. The $Q^{0}$ models have a minimum distance of approach $^{64-65}$ for Si-Si pairs set at $3.5 \AA$ in order to force complete depolymerisation of the silicate part of the glass network. Table 2 lists the parameters of the potentials used, and the Lennard-Jones well depths and radii follow from the Lorentz-Berthelot mixing rules: $\varepsilon_{i j}=\left(\varepsilon_{i} \varepsilon_{j}\right)^{1 / 2}$ and $\sigma_{i j}=\left(\sigma_{i}+\sigma_{j}\right) / 2$. A prime has been used to denote the fact that the parameters for the $\mathrm{Pb}$ atom must be modified in the presence of the lone-pair. The $\mathrm{Pb}^{\prime}-\mathrm{LP}$ separation was set at $r_{P b^{\prime} L P}=1.0 \AA$, as calculated for $\alpha$-PbO by lone-pair localisation methods. ${ }^{66-67}$ This was held essentially constant by setting the coefficient of the intramolecular potential energy ${ }^{68-}$ ${ }^{69}$ to a large value $\left(1 \times 10^{8} \AA^{-1}\right.$ a.m.u. $\left.{ }^{-1 / 2}\right)$, whilst setting the $\mathrm{Pb}^{\prime}$ and $\mathrm{LP}$ masses to be equal, to maximise the reduced mass. In addition, minimum distances of approach were set ${ }^{64-65}$ at: $3.0 \AA$ (Si$\mathrm{Pb}$ ), $3.1 \AA$ ( $\mathrm{Pb}-\mathrm{Pb}), 2.6 \AA \AA$ ( $\mathrm{Si}-\mathrm{LP})$ and $2.7 \AA$ ( $\mathrm{Pb}$ '-LP, intermolecular). The Lennard-Jones, Coulomb and empirical terms of the potentials were each smoothly truncated, as described by Soper. ${ }^{63,70}$ A large cut-off radius of $16 \AA$ was required due to long-range, real-space oscillations of the $\mathrm{Pb}$ - $\mathrm{Pb}$ partial pair distribution. Models were composed of 4400 atoms (2400 O, $400 \mathrm{Si}$ and $1600 \mathrm{~Pb}$ or Pb'-LP) inside a cubic box with periodic boundary conditions and edge length $L=42.92 \AA$, derived from the measured atomic number density (Table 1). A starting model was obtained by successive NVT Monte Carlo equilibrations of the system under the reference potential, at $1300 \mathrm{~K}, 600 \mathrm{~K}$ and finally $300 \mathrm{~K}$, before the empirical potential refinement began. Structural parameters and their distributions are reported as averages over many $\left(>10^{3}\right)$ configurations of the models as they fluctuate about the final equilibrium energy, at which the scattering cross-sections of model and experiment are in good agreement. The maximum allowed amplitude of the empirical potential was $210 \mathrm{~kJ} \mathrm{~mol}^{-1}$, in the ionic and $\mathrm{Q}^{0}$ models, and $164 \mathrm{~kJ} \mathrm{~mol}^{-1}$ in the lone-pair models.

\section{Results}

\section{Distinct Scattering and Correlation Functions}

The program Gudrun $\mathrm{x}^{71-72}$ was used to correct the $\mathrm{x}$-ray data for the effects of polarisation, absorption and multiple scattering, removal of backgrounds, normalisation using the Krogh-Moe ${ }^{73}$ and Norman ${ }^{74}$ method, and extraction of $i^{x}(Q)$ by removal of the self-scattering (including the Compton fraction) and sharpening according to equation 3 (ESI). A small residual background, slowly varying with $Q$, was removed using the top hat convolution method. ${ }^{71,75}$ The neutron diffraction data were corrected, using the GudrunN ${ }^{72}$ software and the Atlas ${ }^{76}$ suite of programs, for absorption, multiple scattering, inelasticity effects, backgrounds, and normalised to obtain $i^{N}(Q)$.

The distinct scattering functions $i^{x}(Q)$ and $i^{N}(Q)$ for the high lead glass are shown in Fig. 1 . The high $Q$ regions show discernible oscillations out to at least $20 \AA^{-1}$ for the $x$-ray function, and $35 \AA^{-1}$ in the 
neutron case. The reason for the difference is partly due to the very high weighting of the $\mathrm{Pb}-\mathrm{Pb}$ pair term for x-ray diffraction, which is more strongly damped in $Q$-space than the $\mathrm{O}-\mathrm{O}$ and $\mathrm{Pb}-\mathrm{O}$ terms which dominate the high $Q$ region of the neutron $i^{N}(Q)$. The implication of this is that the distribution of nearest neighbour $\mathrm{Pb}-\mathrm{Pb}$ interatomic distances is broader than those for $\mathrm{O}-\mathrm{O}$ and $\mathrm{Pb}$ $O$. This becomes clear by inspection of the real-space correlation functions, $T^{R}(r)(R=N$ or $X)$, shown in Fig. 2. Knowledge of the different $x$-ray and neutron weighting functions and of lead silicate crystal structures ${ }^{42-47}$ allows the nearest neighbour peaks to be assigned in accord with previous diffraction based studies on lead silicates. ${ }^{4-15}$ The peak corresponding to the $\mathrm{Si}-\mathrm{O}$ bond length at $1.635(2) \AA$ in $T^{N}(r)$ is practically negligible in $T^{X}(r)$, which shows a first clear peak at $\approx 2.23 \AA$, assigned to short $\mathrm{Pb}-\mathrm{O}$ bonds characteristic of asymmetric sites with stereochemically active lone-pairs. The distribution of $\mathrm{Pb}-\mathrm{O}$ bonds in $T^{X}(r)$ clearly extends further to the high $r$ side, as has been observed for silicate glasses with lower $\mathrm{Pb}$ concentrations by diffraction ${ }^{4-15}$ and EXAFS. ${ }^{16-18}$ Other contributions to $T^{x}(r)$ below $3 \AA$ are negligible. Above $3 \AA, T^{x}(r)$ shows very large amplitude oscillations about the average scattering density $T^{x, 0}(r)$, arising almost solely from the radial distribution of $\mathrm{Pb}-\mathrm{Pb}$ atomic separations, with the nearest neighbour $\mathrm{Pb}-\mathrm{Pb}$ separation at $\approx 3.72 \AA$. Additionally a peak is observed at $\approx 2.67 \AA \AA$ in $T^{N}(r)$, which arises from O-O distances within [SiO $\left.\mathrm{S}_{4}\right]$ tetrahedra.

\section{Correlation Function Peak Fits}

Gaussian distributions, appropriately convolved with the Fourier transform of the Lorch $M(Q)^{77}$ (see ESI) were fitted to the low $r$ peaks of $T^{N}(r)$. First the Si-O peak and the leading edge of the $\mathrm{Pb}-\mathrm{O}$ feature were fitted. The area of the Si-O peak yields $N_{\mathrm{siO}}$, the coordination of silicon by oxygen, and hence $N_{\text {OSi }}$ (equation 14, ESI) which, based on the assumption of a corner sharing tetrahedral silicate subnetwork, can be used to predict the intratetrahedral $\left(\left[\mathrm{SiO}_{4}\right]\right)$ coordination number, $N_{\mathrm{OO}}=3 \mathrm{~N}_{\mathrm{OSi}}$ and hence the peak area, $A_{\mathrm{OO}}$. Furthermore $r_{\mathrm{OO}}=(8 / 3)^{1 / 2} r_{\mathrm{SiO}}$, based on ideal tetrahedral geometry. The contribution of the intratetrahedral O-O separations to $T^{R}(r)$ can then be predicted, providing a final assumption regarding the root mean square (RMS) deviation, $\left\langle u_{00}{ }^{2}\right\rangle^{1 / 2}$, is made, and, to good approximation, the value is considered the same as that measured for pure vitreous silica (see ESI). The residual obtained by subtracting the fitted $\mathrm{Si}-\mathrm{O}, \mathrm{Pb}-\mathrm{O}$ and calculated O-O peaks from $T^{\mathrm{N}}(r)$ shows a peak at $\approx 2.42 \AA$ which is assigned to longer $\mathrm{Pb}-\mathrm{O}$ bonds. Although fitting of multiple symmetric distributions to a clearly asymmetric $\mathrm{Pb}-\mathrm{O}$ bond length distribution is somewhat arbitrary, it provides a convenient means for its characterisation, and the average coordination numbers calculated from the fits can be summed to give a total $N_{\text {Pbo }}$ and hence $N_{\text {OPb }}$. The four bond length distributions derived from $T^{N}(r)$, suitably weighted and broadened for x-rays, were then subtracted from $T^{x}(r)$, revealing a third contribution to the $\mathrm{Pb}-\mathrm{O}$ distribution, centred at $\approx 2.65 \AA$. This was readily resolvable from the extremely low weighted 0-O pair term in the x-ray case, and was then finally adjusted by allowing its parameters to vary in order to best fit $T^{N}(r)$. $T^{x}(r)$ in the region of its strongest peak at $\approx 3.72 \AA$ is strongly dominated by the $\mathrm{Pb}$ - $\mathrm{Pb}$ term and hence this peak was fitted solely in terms of $\mathrm{Pb}-\mathrm{Pb}$ distances (neglecting all other terms, including $\mathrm{Pb}-\mathrm{Si}$ and $\mathrm{Pb}-\mathrm{O}$, as supported by the crystal simulation, Fig. 3 , see below). The results of the fitting are summarised in Table 3 and illustrated in Fig. 3.

\section{Glass Structure Models}

The four EPSR derived glass structure models all yielded good fits to the diffraction data, ${ }^{63}$ with Rfactors (Table 4) close to $2 \times 10^{-3}$. The fits are shown in Figs 4, S5 and S6 and Table 4 lists the total 
energies of the models, showing that the energy is significantly lowered by the introduction of the lone-pairs ( $\mathrm{Pb}$ '-LP dipoles). Fig. 4 compares the ionic and lone-pair model interference functions to those measured by $x$-ray and neutron diffraction. The weighted partial pair interference functions are also displayed, clearly demonstrating the negligible contribution, to the $x$-ray signal, of terms not containing $\mathrm{Pb}$ and the extremely small contribution from the Si-Si terms to both $\mathrm{x}$-ray and neutron diffraction patterns. The main difference between the ionic and lone-pair models is visible in the $\mathrm{O}$ O pair term, particularly for $Q<16 \AA^{-1}$. This is manifest in the $g_{\mathrm{oo}}(r)$, Fig. 5 , as a deviation between the two model distributions at separations beyond the first (intratetrahedral $\left[\mathrm{SiO}_{4}\right]$ ) peak, and is interpreted in terms of a modification of the local structure about the $\mathrm{Pb}$ atoms, due to $\mathrm{LP}$ interactions.

\section{Comparison to Crystalline $\mathrm{Pb}_{11} \mathrm{Si}_{3} \mathrm{O}_{17}$}

It is useful to compare the structure of crystalline $\mathrm{Pb}_{11} \mathrm{Si}_{3} \mathrm{O}_{17}{ }^{45}$ which is close in composition ( $78.57 \mathrm{~mol} \% \mathrm{PbO})$ to the glass. The large unit cell, which contains 22 distinct $\mathrm{Pb}$ sites, makes for a particularly rich comparison. The $T^{R}(r)$ simulated for the crystal using the XTAL program, ${ }^{78}$ along with the appropriately weighted partial pair correlation functions, are shown in Fig. 3. They have been broadened with the same real-space resolution functions as for the experimental results, and for the effects of thermal motion using the RMS deviations in interatomic distances, $\left\langle u_{i j}{ }^{2}\right\rangle^{1 / 2}$, obtained by peak fitting (Table 3), with a constant value $\left\langle u_{i j}{ }^{2}\right\rangle^{1 / 2}=0.15 \AA$ applied at larger distances in the cases where the nearest neighbour value for $\left\langle u_{i j}^{2}\right\rangle^{1 / 2}$ is less than $0.15 \AA$. These are approximations which typically lead to over broadening of the nearest neighbour peaks if significant static disorder is present in the crystal structure, such as for the Si-O peak, Fig. 3.

\section{Discussion}

High lead oxide glass studies

We consider the present structural study to be important, in that the $80 \mathrm{~mol} \% \mathrm{PbO}$ lead silicate has the highest lead content (at.\%) of any oxide glass studied to date, and is well beyond the conventional glass-forming limit of $66.7 \mathrm{~mol} \% \mathrm{PbO}$. The preceeding statement is justified as follows. High lead oxide glasses from $\mathrm{PbO}-\mathrm{M}_{2} \mathrm{O}_{3}$ systems such as the lead borates, ${ }^{79}$ aluminates ${ }^{80}$ and gallates, ${ }^{81-82}$ contain a lower atom percentage $\mathrm{Pb}$ than the $\mathrm{PbO}-\mathrm{MO}_{2}$ glasses, such as the silicates. For example, at 80 mol\% $\mathrm{PbO}$, the $\mathrm{MO}_{2}$ glasses contain 36.4 at.\% $\mathrm{Pb}$ whilst the $\mathrm{M}_{2} \mathrm{O}_{3}$ glasses contain only 30.8 at.\% $\mathrm{Pb}$. An x-ray diffraction study on lead titanate glasses ${ }^{83}$ includes claims of a composition of $90 \mathrm{~mol} \% \mathrm{PbO}$, however, the laboratory $\mathrm{x}$-ray diffraction data are of insufficient quality to rule out $\mathrm{Al}_{2} \mathrm{O}_{3}$ contents (arising from crucible contamination) larger than those stated, and the absence of a Pb-O peak in the radial distribution function was not explained. Takaishi et al. ${ }^{14}$ claimed to have studied an $89 \mathrm{~mol} \% \mathrm{PbO}$ lead silicate glass, however, their radial distribution function is consistent with a much lower $\mathrm{Pb}$ concentration, estimated at $72 \mathrm{~mol} \% \mathrm{PbO}$ from their reported glass density of $7.50 \mathrm{~g} / \mathrm{cm}^{3}$. Combined with the fact that the authors ${ }^{14}$ do not take into account apodization effects, their quoted coordination numbers are subject to large uncertainties. An extremely dense $\left(9.3 \mathrm{~g} / \mathrm{cm}^{3}\right)$ lead silicate glass, with as high as $96 \mathrm{~mol} \% \mathrm{PbO}$, has been reported, ${ }^{84}$ but under the assumption that only a maximum of $4 \mathrm{~mol} \% \mathrm{SiO}_{2}$ entered the melt from the porcelain crucible used. In attempting to replicate the results we obtained a lead aluminosilicate glass of approximate composition $73 \mathrm{PbO} \cdot 17 \mathrm{SiO}_{2} \cdot 10 \mathrm{Al}_{2} \mathrm{O}_{3}$, see ESI. There is also a report of silicate glass formation at $91.2 \mathrm{~mol} \% \mathrm{PbO}^{85}$ although the density is very similar to that measured for the 
$80 \mathrm{~mol} \% \mathrm{PbO}$ glass of the present study and the refractive index reported is close to other reports ${ }^{58-}$

${ }^{59}$ for glasses in the 60 to $70 \mathrm{~mol} \% \mathrm{PbO}$ range.

\section{Short Range Order}

Several key points can be made regarding the peak fit parameters, Table 3. Firstly, the data are consistent with Si species which are four-fold coordinated to oxygen. The average $N_{\mathrm{PbO}}=3.77(2)$ is close to four, whilst showing a distribution of bond lengths, similar to $\mathrm{Pb}_{11} \mathrm{Si}_{3} \mathrm{O}_{17}{ }^{45}$ (see Fig. 3). This is in contrast to $\alpha-\mathrm{PbO}^{48}$ which contains highly uniform $\left[\mathrm{PbO}_{4}\right]$ square pyramids, with a single $\mathrm{Pb}-\mathrm{O}$ bond length of $2.329 \AA$, and indeed to $\beta-\mathrm{PbO}^{49}$ which contains distorted $\left[\mathrm{PbO}_{4}\right]$ pyramids, with two short $(\approx 2.23 \AA)$ and two longer $(2.481 \AA$ ) bonds. The literature on lead silicate glasses, suggests that $N_{\mathrm{PbO}}$ and $N_{\text {Sio }}$ are approximately independent of glass composition and thus $N_{\mathrm{Ox}}(\mathrm{X}=\mathrm{Si}, \mathrm{Pb})$ must change across the glass forming range. In the high lead glass, the average $N_{\text {OSi }}=0.67(2)$ is less than one, and this is independent evidence for some oxygen atoms being bonded only to $\mathrm{Pb}$ in the first coordination shell, and the existence of a plumbite glass network. The total $N_{\mathrm{OPb}}=2.48(2)$ on the other hand, is greater than two. The glass network is therefore not constructed with oxygen coordinated to two cations, as in vitreous $\mathrm{SiO}_{2}$, for example, with the total $N_{\mathrm{OX}}=3.15(3)$.

The $T^{R}(r)$ of the glass and $\mathrm{Pb}_{11} \mathrm{Si}_{3} \mathrm{O}_{17}{ }^{45}$ crystal are similar at short range (Fig. 3 ) and the positions of peaks in the partial pair correlation functions confirm the assignment of the peaks in the glass. $t_{\mathrm{PbO}}(r)$ (eqn (S11), (ESI+)) of the crystal does not drop to zero after the first maximum, as $t_{\mathrm{SiO}}(r)$ does. The residual after peak fitting to $T^{N}(r)$ for the glass, in the $3 \AA$ region, can therefore be assigned to the $\mathrm{Pb}-\mathrm{O}$ and $\mathrm{O}-\mathrm{O}$ partials, on the basis of the $t_{i j}(r)$ simulated for the crystal, which amounts to assuming similar $\mathrm{Pb}-\mathrm{O}-\mathrm{Pb}$ and $\mathrm{Pb}-\mathrm{O}-\mathrm{Si}$ bond angles.

Average coordination numbers, $N_{i j}^{\prime}$ (equation 15, ESI), calculated over the ensembles of model configurations, are given in Table 5, along with their respective distributions (see also ESI Fig. S7). All models contain the majority of lead in $\left[\mathrm{PbO}_{4}\right]$ and $\left[\mathrm{PbO}_{3}\right]$ polyhedra $\left(r_{2}=2.7 \AA\right)$, see Fig. 6 . Bond angle distributions (BADs) for $\mathrm{O}-\mathrm{X}-\mathrm{O}$ and $\mathrm{X}-\mathrm{O}-\mathrm{X}$ triplets are displayed in Fig. 7. The O-Pb-O BAD is broad and asymmetric, peaking close to $80^{\circ}$, but with a broad shoulder spanning the obtuse angle region. This is remarkably similar to the distribution in the crystal $\mathrm{Pb}_{11} \mathrm{Si}_{3} \mathrm{O}_{17}{ }^{45}$ and is therefore characteristic of highly asymmetric $\left[\mathrm{PbO}_{m}\right]$ polyhedra typical of $\mathrm{Pb}$ with $s p^{3}$ or $s p^{3} d$ hybridisation and stereochemically active electron lone-pairs occupying one orbital with greater $p$-character. For comparison, the highly uniform $\left[\mathrm{PbO}_{4}\right]$ pyramids found in $\alpha-\mathrm{PbO}^{48}$ contain four $\mathrm{O}-\mathrm{Pb}-\mathrm{O}$ angles of $74.5^{\circ}$ and two of $117.8^{\circ}$, whilst the more distorted $\left[\mathrm{PbO}_{4}\right]$ pyramids of $\beta-\mathrm{PbO}^{49}$ have corresponding angles of $76.8^{\circ}$ (two), $80.0^{\circ}$ (two), $90.3^{\circ}$ (one) and $146.6^{\circ}$ (one). That is, all three crystalline compounds contain a preponderance of angles close to $80^{\circ}$, but with some larger angles, as is necessary for $\left[\mathrm{PbO}_{m}\right]$ pyramidal geometries with coordination number $m>3$. Inspection of Fig. 6 , which shows part of a single model configuration, confirms that $\mathrm{Pb}$ atoms are highly off-centred within their coordination polyhedra, and that these polyhedra display a distribution of different distortions compared to ideal square or trigonal pyramids. It is also apparent (Fig. 6) that the $\left[\mathrm{PbO}_{m}\right]$ polyhedra often share edges with each other, and with $\left[\mathrm{SiO}_{4}\right]$ tetrahedra, and that voids exist within the plumbite network, which tend to be occupied by electron lone-pairs.

An inspection of the $\mathrm{Pb}_{11} \mathrm{Si}_{3} \mathrm{O}_{17}{ }^{45}$ crystal structure reveals that it too contains edge-sharing $\left[\mathrm{PbO}_{m}\right]$ units, as well as voids occupied by lone-pair electron density, manifest as channels along the $(01 \overline{1})$ 
direction, see Fig. 6. Such features also define the $\alpha^{48}$ and $\beta-\mathrm{PbO}^{49}$ crystal structures, both of which contain $\left[\mathrm{PbO}_{4}\right]$ pyramids which share all of their edges, and within which voids are manifest as extended two-dimensional layers (Fig. 6).

The first peak in $g_{\mathrm{oo}}(r)$ (Fig. 5) at about $2.67 \AA$ arises from $\left[\mathrm{SiO}_{4}\right]$ tetrahedra, whilst the second peak, at $\approx 3.0$ to $3.1 \AA$, corresponds to intrapolyhedral O-O distances within the $\left[\mathrm{PbO}_{m}\right]$. The latter peak is at a shorter distance in the lone-pair model, demonstrating that the polarisation of the $\mathrm{Pb}^{\prime}-\mathrm{LP}$ moieties acts to push the oxygen atoms bonded to the $\mathrm{Pb}$ atom closer together than in the ionic and $\mathrm{Q}^{0}$ models, in accord with VSEPR ${ }^{86-88}$ theory. This is manifest in the difference between the O-Pb-O BADs of the four models (Fig. 7), where the lone-pair results in a larger proportion of smaller bond angles, and hence a more well defined $\left[\mathrm{PbO}_{m}\right]$ local geometry. There are striking differences between the O-Pb-O BADs in Fig. 7 and that extracted by Kohara et al., ${ }^{15}$ by RMC, for a lead silicate glass containing 65 mol\% PbO. The RMC derived O-Pb-O BAD is broader, extending from 50 to $180^{\circ}$, with a poorly defined peak close to $60^{\circ}$. Despite differences in glass composition between the two studies, this is suggestive that RMC and EPSR are capable of deriving qualitatively different models that are both consistent with the same diffraction data sets; although we note that the real-space resolution of our neutron diffraction data is higher. We plan to extend our study in the future to allow a more direct comparison between models for glasses of the same compositions. A point in favour of the EPSR approach is the qualitative similarity between the O-Pb-O BADs of the model glass and the crystal $\mathrm{Pb}_{11} \mathrm{Si}_{3} \mathrm{O}_{17}{ }^{45}$ The model $\mathrm{Pb}-\mathrm{O}-\mathrm{Pb} \mathrm{BADs}$ are also similar to this crystal (Fig. 7). The mean $\mathrm{Pb}-\mathrm{O}-\mathrm{Pb}$ angles (Table 4) are all close to $110^{\circ}$, similar to the $106.8^{\circ}$ in $\mathrm{Pb}_{11} \mathrm{Si}_{3} \mathrm{O}_{17},{ }^{45}$ whilst the RMS deviations (Table 4) are slightly larger than the $9.3^{\circ}$ of the crystal. Therefore there is a tendency for the oxygen atom environment to be similar to the $\left[\mathrm{OPb}_{4}\right]$ distorted tetrahedral geometry which is present in $\alpha-\mathrm{PbO}^{48}$ (mean angle $109.6^{\circ}$ with RMS deviation $5.8^{\circ}$ ).

Oxygen may form bonds with more than one element giving [OSi $\mathrm{OPb}_{\mathrm{q}}$, and Table $\mathrm{S} 2$ of the ESI details the speciation for crystalline $\mathrm{Pb}_{11} \mathrm{Si}_{3} \mathrm{O}_{17}{ }^{45}$ as [OPbSi], [OPb $2 \mathrm{Si}$ ] and [ $\mathrm{OPb}_{4}$ ] in approximately equal proportions, when considering short $\mathrm{Pb}-\mathrm{O}$ bonds only $\left(r_{2}=2.7 \AA\right)$. When longer $\mathrm{Pb}-\mathrm{O}$ bonds are included $\left(r_{2}=3.27 \AA\right)$, the majority of oxygen atoms are coordinated to four cations, either [ $\left.\mathrm{OSiPb}_{3}\right]$ or $\left[\mathrm{OPb}_{4}\right]$. A minority of the longer $\mathrm{Pb}-\mathrm{O}$ bonds are to bridging oxygen atoms (i.e. [OSi $\mathrm{O}_{2} \mathrm{~Pb}$ ] species). The distributions of $\left[\mathrm{OSi}_{\mathrm{p}} \mathrm{Pb}_{\mathrm{q}}\right]$ species in the glass models have not been quantified. Nevertheless, their $\mathrm{O}-\mathrm{Si}$ and $\mathrm{O}-\mathrm{Pb}$ coordination number distributions are similar to those of the crystal (Table 5), although slightly broader. Therefore it is likely that the distribution of $\left[\mathrm{OSi}_{\mathrm{p}} \mathrm{Pb}_{\mathrm{q}}\right.$ ] species in the models are also similar to those of the crystal (Table S2, ESI).

Fig. 8 shows the LP-LP partial pair correlation function, $g_{\text {LPLP }}(r)$, and the nearest neighbour LP-LP distance at $2.85 \AA$ is significantly lower than that for $\mathrm{Pb}^{\prime}-\mathrm{Pb}^{\prime}$ at $3.68 \AA$. Hence one can infer a net 'effective attractive interaction' between the negative poles of the Pb'-LP dipoles. In fact, if one decorates the $\alpha-\mathrm{PbO}^{48}$ crystal structure with lone-pairs (Fig. 6) by lone-pair localisation methods, ${ }^{66-67}$ one obtains a nearest neighbour distance $r_{L P L P}=2.88 \AA$, corresponding to the distance between the lone-pairs which fill the interlayer spaces of the crystal. Since the only LP-LP interaction term defined by the reference potential during modelling was the repulsive Coulomb term, the 'effective attractive interaction' is a direct consequence of the packing requirements of the system under the specified density and the constraints arising from the other pairwise interactions, including attractive ('intermolecular') Pb-LP forces. It is not imposed by the diffraction data via the empirical potential because it is observed in the Monte Carlo simulations performed prior to the introduction 
of the data (Fig. 8) and empirical potential refinement. Hence we conclude that the free volume found in RMC models of lead silicate glasses by Kohara et al. ${ }^{15}$ arises as a result of stereochemically active lone-pairs in the glasses. Notably, the voids visible in Fig. 6, within the lone-pair model, are less apparent in the ionic and $Q^{0}$ models.

Although the $\mathrm{O}-\mathrm{X}-\mathrm{O}$ and $\mathrm{Pb}-\mathrm{O}-\mathrm{Pb}$ BADs of the glass models and $\mathrm{Pb}_{11} \mathrm{Si}_{3} \mathrm{O}_{17}{ }^{45}$ are similar, Fig. 7 shows that the Si-O-Si BAD of the crystal resembles only those of the depolymerised, $Q^{0}$ and $Q^{0}+L P$, models. The crystal contains $\mathrm{Q}^{0},\left[\mathrm{SiO}_{4}\right]^{4-}$, monomers and $\mathrm{Q}^{1},\left[\mathrm{Si}_{2} \mathrm{O}_{7}\right]^{6-}$, dimers only, and it is the large $\mathrm{Si}-\mathrm{O}-\mathrm{Si}$ bond angles of the dimers that comprise the BAD shown in Fig. 7. The large proportion of smaller bond angles in the ionic and lone-pair models of the glass is indicative of more highly polymerised silicate units. The reason for their existence is discussed in the following section, and was the motivation behind the derivation of the depolymerised models.

\section{Si Q-speciation and the uniqueness of the models}

A problem with empirical modelling based on diffraction data occurs when a given species is sufficiently dilute that some or all of its contributions to the distinct scattering are negligible with respect to other terms. This is the case for the Si-Si pair term (Fig. 1) of the high lead silicate glass, and is compounded by the relatively small atomic number and neutron scattering length of Si. Fig. 4 clearly illustrates the fact that the $\mathrm{Si}-\mathrm{Si}$ terms are negligible for both radiation types. The result is that the functions $S_{\text {Sisi }}(Q)$ and $g_{\text {sisi }}(r)$ are effectively constrained only indirectly by the diffraction data, and their structure arises primarily from the constraints of the average density and, in the case of EPSR, the reference potentials. Hence $S_{\text {sisi }}(Q)$ and $g_{\text {sisi }}(r)$ are the most poorly determined pair terms.

A commonly discussed feature of the intermediate range order in silicate glasses is the $Q^{n}$ species distribution, where $n$ is the number of bridging oxygen atoms about a $\mathrm{Si}$, or, equivalently, the nearest neighbour Si-Si coordination number. ${ }^{29} \mathrm{Si}$ MAS NMR has had a tremendous impact in this field, since it is possible to estimate the Q-species distribution from the chemical shift distribution of the spectrum. This technique has been applied to a series of lead silicate glasses, ${ }^{23}$ made in the same manner as that reported here, and allows for an independent test of the empirically derived glass structure models. Table 5 gives the Si-Si coordination number distributions (CNDs) of the models, alongside the equivalent values derived from ${ }^{29} \mathrm{Si} \mathrm{MAS} \mathrm{NMR.}{ }^{23}$ It is clear that the ionic and lone-pair models are over-polymerised with respect to the interpretation of the NMR data, and this in turn implies that a larger fraction of oxygen is contained within the plumbite subnetwork of the models than is indicated by the NMR measurements on the glass. It is these "plumbite oxygens" which provide strong evidence for a plumbite subnetwork, i.e. regions of the glass in which the connectivity involves only lead and oxygen. The abundance of these oxygen species is intrinsically linked with the number of bridging oxygen atoms, and overpolymerisation of the silicate network naturally leads to an overestimation of the plumbite oxygen fraction. This is clear in the O-Si coordination number distributions of Table 5 where it can be seen that the (close to) complete depolymerisation enforced in the $Q^{0}$ and $Q^{0}+L P$ models results in a smaller plumbite oxygen fraction (oxygen bonded to zero silicon atoms) as compared to the ionic and lone-pair models, and better agreement with the values derived from ${ }^{29} \mathrm{Si} \mathrm{MAS} \mathrm{NMR}{ }^{23}$ and for $\mathrm{Pb}_{11} \mathrm{Si}_{3} \mathrm{O}_{17}{ }^{45}$ (also see ESI, Fig. S7).

Kohara et al. ${ }^{15}$ derived an RMC model of a lead silicate glass with $65 \mathrm{~mol} \% \mathrm{PbO}$ which is underpolymerised compared to ${ }^{29}$ Si MAS NMR data ${ }^{14,22-23}$ on glasses of the same composition. Interatomic 
potentials play no part in the RMC method, and hence it would appear that the over-polymerisation of the EPSR models occurs as a result of $\mathrm{Si}$ clustering under the influence of the interatomic potentials. This situation requires addressing, in both RMC and EPSR cases, and work is underway to improve the models by introducing reference potential terms which act to drive them toward the experimentally determined $Q^{n}$ species distributions. In the $Q^{0}$ and $Q^{0}+L P$ models, this was achieved, using a crude but effective means, by forcing Si-Si pairs to be at least $3.5 \AA$ apart. The result is that the vast majority (97.9(7) \%) of silicate anions exist as $Q^{0}$ monomers (Table 5, ESI Fig. S7). The remaining 2.1(7) $\%$ are present as $Q^{1}$ dimers with large Si-O-Si bond angles, Fig. 7. The fact that models with different $Q^{n}$ species distributions have similar R-factors (Table 4 ) demonstrates the non-uniqueness of the model fits to the diffraction data, and emphasises the insensitivity of the diffraction data to Si-Si correlations. However, it is important to note the robustness of other features, particularly the $\mathrm{Pb}-\mathrm{O}$ and $\mathrm{Pb}-\mathrm{Pb}$ partial pair distribution functions (Fig. 5) and the $\mathrm{O}-\mathrm{Pb}-\mathrm{O}$ and $\mathrm{Pb}-\mathrm{O}-\mathrm{Pb}$ BADs (Fig. 7). Comparing the ionic model to the $\mathrm{Q}^{0}$ model (Fig 5 and Table 5 ) shows that the distributions of short $(<2.7 \AA) \mathrm{Pb}-\mathrm{O}$ bonds and coordination numbers are unaffected, whilst subtle changes occur within the longer $(2.7<r<3.27 \AA)$ bond length region, which effectively compensate for the changes visible in the $\mathrm{O}-\mathrm{O}$ term, resulting in slightly higher $\mathrm{Pb}-\mathrm{O}$ coordination in this region. Other changes concomitant with the change in Q-species distribution (ESI equations S16 to S18) occur in the O-X CNDs (Table 5, ESI Fig. S7) and in the Pb-Si pair distribution (Fig. 5), with the depolymerisation of the silicate anions resulting in a higher $\mathrm{Pb}-\mathrm{Si}$ nearest neighbour coordination number.

\section{Intermediate Range Order}

The first sharp diffraction peak (FSDP) is a consequence of ordering on length scales beyond nearest neighbour correlations. The distinct x-ray and neutron scattering functions (Fig. 1 ) both show this clear, sharp peak at $Q_{1}=2.04(1) \AA^{-1}$, as well as a pre-peak at $Q_{0}=1.06(1) \AA^{-1}$, which is much more clearly evident in $i^{N}(Q)$. Table 6 lists the positions and widths of the two peaks extracted by fitting of Lorentzian lineshapes ${ }^{89}$ to their leading edges, along with their associated periodicities and correlation lengths. It is clear from Fig. 4 that the FSDP arises predominantly from $\mathrm{Pb}-\mathrm{Pb}$ separations, and that the periodicity of $3.08(2) \AA$ can be related to that of the $x$-ray $T^{x}(r)$ (Fig 2), which is dominated by the $\mathrm{Pb}-\mathrm{Pb}$ partial correlation function (Fig. 5). The extent of the real-space oscillations, implied by the large correlation length of 19.6(6) $\AA$, is most clearly evident in Fig. S8 of the ESI which shows $D^{x}(r)=T^{x}(r)-T^{x, 0}(r)$ out to $30 \AA$. Table 6 also lists the parameters of the FSDP of vitreous silica, ${ }^{89}$ which has a larger periodicity $(4.11(5) \AA$ ) and a shorter correlation length (10.0(3) $\AA$ ) associated with it. Therefore the plumbite glass network is characterised by greater medium range order compared to the silicate network (of pure $\mathrm{SiO}_{2}$ glass). This appears to be a consequence of the compact nature of the plumbite network, which is characterised by high oxygen-cation coordination numbers, significant edge-sharing of $\left[\mathrm{PbO}_{m}\right]$ units and the presence of sterically active electron lonepairs which organise to create voids in the glass network, see Fig. 6. These voids are typically separated by single chains or layers of the plumbite network, with similar character (LP organisation) to regions found within the related crystalline materials.

A pre-peak similar to that observed here has previously been observed by neutron diffraction from high lead ( $\geq 50$ mol\% PbO) silicate glasses, ${ }^{10-12,14-15}$ lying at approximately $1.2 \AA^{-1}$, as well as from high lead aluminate ${ }^{80}$ and gallate ${ }^{81-82}$ glasses. The partial structure factors extracted by modelling (Fig. 4 , ESI Fig. S4) indicate that the Si-O and O-O terms are the main contributors to the $Q_{0}=1.06(1) \AA^{-1}$ 
feature, and hence we conclude that it arises from the broad distribution of nearest-neighbour distances between dispersed silicate anions, presumably those which are separated by chains or layers of the plumbite network. The pre-peak has a longer periodicity than for the lower lead silicate glasses that have been studied previously, ${ }^{10-12,14-15}$ which is consistent with the more dilute silicate anions having, on average, a larger separation. This average silicate anion-anion separation can be calculated from glass density, $\rho_{0}$, the atomic fraction of silicon, $c_{S i}$, and the $Q^{n}$ distribution, giving $r_{Q}=\left(\frac{2 Q^{1}+Q^{0}}{c_{\mathrm{Si}} \rho_{0}}\right)^{1 / 3}$,

which yields $r_{Q}\left(100 \% Q^{0}\right)=5.8 \AA, r_{Q}\left(100 \% Q^{1}\right)=7.3 \AA$ and $r_{Q}(\mathrm{NMR})=6.3 \AA$ using the ${ }^{29} \mathrm{Si}$ MAS NMR derived ${ }^{23} Q^{n}$ speciation (neglecting the $3 \% Q^{2}$ ). Although this approach neglects the size and shape of the anions, the fact that $r_{Q}(\mathrm{NMR})$ is greater than the periodicity of 5.94(6) $\AA$ implies that the silicate anions are inhomogeneously distributed within the glass. The fact that $r_{Q}\left(100 \% Q^{0}\right)$ is less than the periodicity $(5.94(6) \AA)$ is indirect evidence for residual polymerisation of the silicate subnetwork, and the existence of $Q^{1}$, or more highly polymerised, units. Indeed, this statement is supported by the small shift in the position of the diffraction peak to higher $Q\left(\approx 1.10 \AA^{-1}\right)$ in the $Q^{0}$ model (ESI Fig. S6) which implies a periodicity of only $\approx 5.7 \AA$.

Interrogation of the ionic and lone-pair models, reveals that most ( $\sim 87 \%) \mathrm{Pb}$ atoms have a Si atom within $4.2 \AA$ (ESI Fig. S7) and rising to $93 \%$ in the $Q^{0}$ model (ESI, Fig. S7). Considering the overestimation of the numbers of bridging ( $\mathrm{Si}-\mathrm{O}-\mathrm{Si})$ and plumbite $\left(\mathrm{Pb}-\mathrm{O}-\mathrm{Pb}_{\mathrm{q}}\right)$ oxygen in the former two models, it is conceivable that at least one $\mathrm{Si}$ is required within the nearest neighbour cation shell around each $\mathrm{Pb}$ to help stabilise the supercooled melt against crystallisation.

The limit of glass formation in the $\mathrm{PbO}^{-\mathrm{SiO}_{2}}$ system?

If there were no plumbite oxygens and no plumbite subnetwork, then the limit of glass formation would be $66.7 \mathrm{~mol} \% \mathrm{PbO}$, at which composition all oxygens are non-bridging and all silicate anions are $Q^{0}$ monomers. Since lead silicate glasses form beyond this limit, this raises the question of what is it that limits glass formation, and similarly, why does a pure PbO glass not form? It is, however, important to note that the limit of glass formation is not a precisely defined composition, because it depends on the glass preparation method, and there are conflicting reports of the limit. For the rapid twin-roller quenching method used to prepare our sample the limit of glass formation is around 83 mol\% $\mathrm{PbO}^{23}$ On the one hand, Bansal and Doremus have given the upper limit of glass formation by normal quenching as $74 \mathrm{~mol} \% \mathrm{PbO}^{90}$ and Mazurin et al. have similarly given the upper limit as 75 mol\% PbO, ${ }^{91}$ whilst on the other hand Kohara et al. ${ }^{15}$ state that it is well known that glasses can be formed up to $90 \mathrm{~mol} \% \mathrm{PbO}$. There is a claim in the literature of glass formation at 96 mol\% $\mathrm{PbO},{ }^{84}$ but this is almost certainly not reliable (see ESI S1). There is also a report of glass formation at $91.2 \mathrm{~mol} \% \mathrm{PbO}^{85}$ although the refractive index and density reported imply a much lower $\mathrm{PbO}$ content. The SciGlass database ${ }^{58-59}$ does not give any other reports of glass formation or properties for more than $75 \mathrm{~mol} \% \mathrm{PbO}$, but gives many reports for compositions of $75 \mathrm{~mol} \% \mathrm{PbO}$ and less. One of the reasons for differing reports of the high PbO limit for glass formation is that it depends on the glass preparation method; different preparation methods have different quench rates, and a glass can only be formed if the quench rate is rapid in comparison with the timescales 
involved in the crystallisation process. Thus it is worthwhile to consider the factors which may limit or promote glass formation, even though the exact limit is not known reliably.

It should be noted that the silicate subnetwork retains some degree of polymerisation right up to $83 \mathrm{~mol} \% \mathrm{PbO},{ }^{23}$ and therefore the number of oxygens bonded only to $\mathrm{Pb}$ is not minimised (as in the $100 \% \mathrm{Q}^{0}$ case). This can be envisaged as an equilibrium between $\mathrm{Pb}-\mathrm{O}-\mathrm{Si}$ links and a mix of $\mathrm{Pb}-\mathrm{O}-\mathrm{Pb}$ and $\mathrm{Si}-\mathrm{O}-\mathrm{Si}$ links. The presence of $\mathrm{Pb}-\mathrm{O}-\mathrm{Pb}$ entities is related to the presence of edge-sharing $\left[\mathrm{PbO}_{m}\right]$ polyhedra, increasing the fraction of which will ultimately destabilise glass formation, the fully edgeshared $\mathrm{PbO}$ crystals being the limiting case. The broad distribution of local Pb environments also plays a role, similar to the distribution of $\mathrm{Si}-\mathrm{O}-\mathrm{Si}$ bond and torsion angles in $\mathrm{SiO}_{2}$ glass, providing flexibility to allow for disordered network formation. Thus it seems that sufficient corner-sharing and local Pb environment disorder, combined with silicate anions with a (relatively) broad $\mathrm{Q}$ species distribution, are required to hinder crystallisation kinetics and allow glass formation. Notably, $\mathrm{MgO}-$ $\mathrm{SiO}_{2}$ glasses can be formed right up to the conventional glass forming limit of $66.7 \mathrm{~mol} \% \mathrm{MgO},{ }^{92-93}$ using containerless levitation techniques, and, at $66.7 \mathrm{~mol}^{2} \mathrm{MgO}$, are more highly polymerised ${ }^{94-95}$ than the stoichiometric mineral enstatite, which is purely $\mathrm{Q}^{0}$. Another example is the $\mathrm{Li}_{2} \mathrm{O}-\mathrm{SiO}_{2}$ system, for which glass formation has been observed almost up to the orthosilicate $\left(66.7\right.$ mol\% $\mathrm{M}_{2} \mathrm{O}$ ) composition, at which point a degree of silicate anion polymerisation remains ${ }^{96}$ Recently, however, it has been demonstrated that a purely $Q^{0}$ glass can be obtained, ${ }^{97}$ for aerodynamically levitated $72\left(\mathrm{Ca}_{0.5} \mathrm{Mg}_{0.5} \mathrm{O}\right) .28 \mathrm{SiO}_{2}$. In this case the structural and topological frustration required to prevent crystallisation comes not from a distribution of $\mathrm{Q}$ species, but from the dissimilarity of the $\mathrm{Ca}^{2+}$ and $\mathrm{Mg}^{2+}$ cations. On this basis alone one would not expect a purely $\mathrm{Q}^{0}$ lead silicate glass to form, but it is interesting to consider the possibility of using aerodynamic levitation to increase the accessible glass-forming range. Foreseeable problems with this include the volatilisation of lead from the molten droplet, and the necessity for careful control of the redox conditions to prevent formation of metallic or tetravalent lead.

\section{Conclusions}

A glass of composition $80 \mathrm{PbO} .20 \mathrm{SiO}_{2}$ can be formed by rapid roller-quenching. Contributions to the stabilisation of the glass come from the presence of: (i) a distribution of $Q^{n}$ silicon species; (ii) a distribution of different $\left[\mathrm{PbO}_{m}\right]$ pyramidal units and (iii) a plumbite subnetwork with a mix of corner and edge-sharing. The practical limit to glass-formation may occur when the fraction of edge-sharing becomes too large to support a random network.

Introduction of $\mathrm{Pb}$ into some of the structural models as dipolar entities, to represent the electron lone-pair on $\mathrm{Pb}^{2+}$, demonstrates that the lone-pairs organise to create voids within the glass network, just as in crystalline materials, such as $\alpha-\mathrm{PbO},{ }^{48}$ where lone-pairs occupy interlayer spaces, with nearest neighbour distance $2.88 \AA$, the same as that found for the models of the glass $(2.85 \AA)$.

The distributions of coordination numbers and bond angles (O-Pb-O and $\mathrm{Pb}-\mathrm{O}-\mathrm{Pb}$ ) in $80 \mathrm{PbO} .20 \mathrm{SiO}_{2}$ glass, obtained by empirical potential structure refinements of neutron and $x$-ray diffraction patterns, provide strong evidence for structural similarity to related crystalline compounds. These include primarily the lead silicate $\mathrm{Pb}_{11} \mathrm{Si}_{3} \mathrm{O}_{17}{ }^{45}$ and, to a lesser extent, the $\alpha$ and $\beta$ polymorphs of lead monoxide, all of which contain $\mathrm{Pb}$ at the apex of pyramidal polyhedra, and $\mathrm{O}$ at the centre of tetrahedron-like geometries, owing to the significant $p$-character and hence stereochemical activity of the $\mathrm{Pb}$ electron lone-pair. 
Four structural models could be derived, with similarly good agreement with the diffraction data, but with appreciable differences in structure. This highlights the need for care when drawing conclusions from such analyses. What is more, the models show qualitative differences to published results $^{15}$ on lead silicate glasses (containing less $\mathrm{Pb}$ ) using reverse Monte Carlo modelling. In particular, the $\mathrm{O}-\mathrm{Pb}-\mathrm{O}$ bond angle distributions are more highly structured as a result of the use of interatomic potentials in the present study, showing greater similarity to the distributions in the aforementioned crystalline systems.

The contribution from Si-Si pairs to the diffraction pattern is negligible, in the case of both neutrons and $x$-rays, due to dilution and small scattering factors. This leads to an overpolymerised silicate subnetwork in unconstrained models, as compared to ${ }^{29} \mathrm{Si}$ MAS NMR results. Models which reproduce the diffraction data at least equally well, were derived, within which the silicate anions were forced to completely depolymerise into monomeric $\left[\mathrm{SiO}_{4}\right]^{4-}$ units, and hence the robustness of the conclusions regarding the plumbite part of the network demonstrated. Work is underway to incorporate more sophisticated constraints from ${ }^{29} \mathrm{Si}$ MAS NMR to drive the models toward the correct $Q^{n}$ speciations.

\section{Acknowledgements}

This work was funded by the STFC Centre for Materials Physics and Chemistry under Grant CMPC09105 and the EPSRC and NSF-DMR grant 0904615. Dr. Emma Barney is thanked for commenting on the manuscript. 


\section{References}

1. W. H. Dumbaugh and J. C. Lapp, J. Am. Ceram. Soc., 1992, 75, 2315-2326.

2. $\quad$ S. R. Friberg and P. W. Smith, IEEE J. Quantum Electron., 1987, 23, 2089-2094.

3. E. R. Barney, A. C. Hannon, N. Laorodphan and D. Holland, J. Phys. Chem. C, 2011, 115, 14997-15007.

4. M. Imaoka and A. Hasegawa, Journal of the Ceramic Association, Japan, 1980, 88, 141-150.

5. H. Morikawa, Y. Takagi and H. Ohno, J. Non-Cryst. Solids, 1982, 53, 173-182.

6. H. Ohno, K. Igarashi, Y. Takagi, H. Toratani, K. Furukawa, J. Mochinaga, T. Nakamura and T. Izumitani, J Jpn I Met, 1983, 47, 132-141.

7. H. Hasegawa and M. Imaoka, J. Non-Cryst. Solids, 1984, 68, 157-158.

8. H. Morikawa, Y. Takagi and H. Ohno, J Non-Cryst Solids, 1984, 68, 159-162.

9. M. Imaoka, H. Hasegawa and I. Yasui, J Non-Cryst Solids, 1986, 85, 393-412.

10. K. Yamada, A. Matsumoto, N. Niimura, T. Fukunaga, N. Hayashi and N. Watanabe, J Phys Soc Jpn, 1986, 55, 831-837.

11. K. Suzuya, D. L. Price, M. L. Saboungi and H. Ohno, Nucl Instrum Meth B, 1997, 133, 57-61.

12. K. Suzuya, S. Kohara and H. Ohno, Jpn J Appl Phys 1, 1999, 38, 144-147.

13. U. Hoppe, R. Kranold, A. Ghosh, C. Landron, J. Neuefeind and P. Jovari, J Non-Cryst Solids, 2003, 328, 146-156.

14. T. Takaishi, M. Takahashi, J. Jin, T. Uchino, T. Yoko and M. Takahashi, J. Am. Ceram. Soc., 2005, 88, 1591-1596.

15. S. Kohara, H. Ohno, M. Takata, T. Usuki, H. Morita, K. Suzuya, J. Akola and L. Pusztai, Physical Review B, 2010, 82, 134209 134201-134207.

16. F. Fayon, C. Landron, K. Sakurai, C. Bessada and D. Massiot, J Non-Cryst Solids, 1999, 243, 3944.

17. V. R. Mastelaro, E. D. Zanotto, N. C. Lequeux and R. Cortes, J. Non-Cryst. Solids, 2000, 262, 191-199.

18. J. Rybicki, A. Rybicka, A. Witkowska, G. Bergmanski, A. Di Cicco, M. Minicucci and G. Mancini, J Phys-Condens Mat, 2001, 13, 9781-9797.

19. H. Hosono, H. Kawazoe and T. Kanazawa, Journal of the Ceramic Association, Japan, 1982, 90, 544-551.

20. E. Lippmaa, A. Samoson, M. Magi, R. Teeaar, J. Schraml and J. Gotz, J. Non-Cryst. Solids, 1982, 50, 215-218.

21. R. Dupree, N. Ford and D. Holland, Phys Chem Glasses, 1987, 28, 78-84.

22. F. Fayon, C. Bessada, D. Massiot, I. Farnan and J. P. Coutures, J Non-Cryst Solids, 1998, 232, 403-408.

23. S. Feller, G. Lodden, A. Riley, T. Edwards, J. Croskrey, A. Schue, D. Liss, D. Stentz, S. Blair, M. Kelley, G. Smith, S. Singleton, M. Affatigato, D. Holland, M. E. Smith, E. I. Kamitsos, C. P. E. Varsamis and E. Ioannou, J. Non-Cryst. Solids, 2010, 356, 304-313.

24. L. Leventhal and A. J. Bray, Phys Chem Glasses, 1965, 6, 113-125.

25. T. Yoko, K. Tadanaga, F. Miyaji and S. Sakka, J. Non-Cryst. Solids, 1992, 150, 192-196.

26. B. M. J. Smets and T. P. A. Lommen, J. Non-Cryst. Solids, 1982, 48, 423-430.

27. P. W. Wang and L. P. Zhang, J. Non-Cryst. Solids, 1996, 194, 129-134.

28. I. A. Gee, D. Holland and C. F. McConville, Phys Chem Glasses, 2001, 42, 339-348.

29. K. N. Dalby, H. W. Nesbitt, V. P. Zakaznova-Herzog and P. L. King, Geochim Cosmochim Ac, 2007, 71, 4297-4313.

30. T. Furukawa, S. A. Brawer and W. B. White, J Mater Sci, 1978, 13, 268-282.

31. C. A. Worrell and T. Henshall, J. Non-Cryst. Solids, 1978, 29, 283-299.

32. B. Piriou and H. Arashi, High Temp Sci, 1980, 13, 299-313.

33. L. P. Liu, Z Phys B Con Mat, 1993, 90, 393-399.

34. D. D. Meneses, M. Malki and P. Echegut, J. Non-Cryst. Solids, 2006, 352, 769-776.

35. K. V. Damodaran, B. G. Rao and K. J. Rao, Phys Chem Glasses, 1990, 31, 212-216. 
36. G. Cormier, T. Peres and J. A. Capobianco, J Non-Cryst Solids, 1996, 195, 125-137.

37. J. Rybicki, W. Alda, A. Rybicka and S. Feliziani, Comput Phys Commun, 1996, 97, 191-194.

38. T. Peres, D. A. Litton, J. A. Capobianco and S. H. Garofalini, J. Non-Cryst. Solids, 1997, 221, 3446.

39. T. Peres, D. A. Litton, J. A. Capobianco and S. H. Garofalini, Philos Mag B, 1998, 77, 389-396.

40. A. Rybicka, J. Rybicki, A. Witkowska, S. Feliziani and G. Mancini, Computational Methods in Science and Technology, 1999, 5, 67-74.

41. G. Bergmanski, M. Bialoskorski, M. Rychcik-Leyk, A. Witkowska, J. Rybicki, G. Mancini, S. Frigio and S. Feliziani, Task Quarterly, 2004, 8, 393-412.

42. M. L. Boucher and D. R. Peacor, Z Kristallogr Krist, 1968, 126, 98-111.

43. L. S. D. Glasser, R. A. Howie and R. M. Smart, Acta Crystallogr B, 1981, 37, 303-306.

44. K. Kato, Acta Crystallographica, 1980, B36, 2539-2545.

45. K. Kato, Acta Crystallographica, 1982, B38, 57-62.

46. S. V. Krivovichev and P. C. Burns, Zapiski Vserossijskogo Mineralogicheskogo Obshchestva, 2004, 133, 70-76.

47. W. Petter, A. B. Harnik and U. Keppler, Zeitschrift Fur Kristallographie Kristallgeometrie Kristallphysik Kristallchemie, 1971, 133, 445-458.

48. R. G. Dickinson and J. B. Friauf, J Am Chem Soc, 1924, 46, 2457-2463.

49. R. J. Hill, Acta Crystallogr C, 1985, 41, 1281-1284.

50. K. Fajans and N. J. Kreidl, J Am Ceram Soc, 1948, 31, 105-114.

51. K. H. Sun, J. Am. Ceram. Soc., 1947, 30, 277-281.

52. A. C. Wright, in Experimental Techniques of Glass Science, eds. C. J. Simmons and O. H. ElBayoumi, American Ceramic Society, Westerville1993, pp. 205-314.

53. R. L. McGreevy, J. Phys.: Condens. Matter, 2001, 13, R877-R913.

54. R. L. McGreevy and P. Zetterström, J. Non-Cryst. Solids, 2001, 293-295, 297-303.

55. A. K. Soper, Phys. Rev. B, 2005, 72.

56. A. J. Havel, S. A. Feller, M. Affatigato and M. Karns, Glass Technol.: Eur. J. Glass Sci. Technol. A, 2009, 50, 227-229.

57. A. J. Havel, S. A. Feller, M. Affatigato, M. Karns and M. Karns, Glass Technol-Part A, 2009, 50, 227-229.

58. SciGlass Professional 7.3, ITC Inc.2008.

59. O. V. Mazurin, M. V. Strel'tsina, T. P. Shvaiko-Shvaikovskaya and A. O. Mazurina, Glass Phys. Chem, 2003, 29, 555-570.

60. H. F. Poulsen, J. Neuefeind, H. B. Neumann, J. R. Schneider and M. D. Zeidler, J. Non-Cryst. Solids, 1995, 188, 63-74.

61. J. A. Bearden and A. F. Burr, Rev. Mod. Phys., 1967, 39, 125.

62. A. C. Hannon, Nuclear Instruments and Methods in Physics Research Section A-Accelerators Spectrometers Detectors and Associated Equipment, 2005, 551, 88-107.

63. A. K. Soper, Phys Rev B, 2005, 72, 104204.

64. A. K. Soper, J Phys-Condens Mat, 2010, 22, 404210.

65. A. K. Soper, J Phys-Condens Mat, 2011, 23, 365402.

66. C. Pirovano, M. S. Islam, R. N. Vannier, G. Nowogrocki and G. Mairesse, Solid State lonics, 2001, 140, 115-123.

67. D. Lebellac, J. M. Kiat and P. Garnier, J Solid State Chem, 1995, 114, 459-468.

68. D. T. Bowron and S. Diaz-Moreno, J Phys Chem B, 2009, 113, 11858-11864.

69. A. K. Soper, Chemical Physics, 2000, 258, 121-137.

70. A. K. Soper, Chemical Physics, 1996, 202, 295-306.

71. A. K. Soper and E. R. Barney, J. Appl. Cryst., 2011, 44, 714-726.

72. A. K. Soper, Rutherford Appleton Laboratory Technical Report, RAL-TR-2011-013, 2011.

73. J. Krogh-Moe, Acta Cryst., 1956, 9, 951-953.

74. N. Norman, Acta Cryst., 1957, 10, 370-373. 
75. A. K. Soper, Mol. Phys., 2009, 107, 1667-1684.

76. A. C. Hannon, W. S. Howells and A. K. Soper, Inst Phys Conf Ser, 1990, 193-211.

77. E. Lorch, Journal of Physics C: Solid State Physics, 1969, 2, 229.

78. A. C. Hannon, Rutherford Appleton Laboratory Technical Report, RAL-93-063, 1993.

79. T. Takaishi, J. S. Jin, T. Uchino and T. Yoko, J Am Ceram Soc, 2000, 83, 2543-2548.

80. E. R. Barney, A. C. Hannon, D. Holland, D. Winslow, B. Rijal, M. Affatigato and S. A. Feller, J Non-Cryst Solids, 2007, 353, 1741-1747.

81. A. C. Hannon, J. M. Parker and B. Vessal, J Non-Cryst Solids, 1998, 232, 51-58.

82. A. C. Hannon, J. M. Parker and B. Vessal, J Non-Cryst Solids, 1996, 196, 187-192.

83. Y. Dimitriev, V. Mihailova and E. Gattef, Phys Chem Glasses, 1993, 34, 114-116.

84. C. Dayanand, G. Bhikshamaiah and M. Salagram, Mater Lett, 1995, 23, 309-315.

85. E. Ellis, D. W. Johnson, A. Breeze, P. M. Magee and P. G. Perkins, Philos Mag B, 1979, 40, 125-137.

86. R. J. Gillespie and E. A. Robinson, Angewandte Chemie-International Edition, 1996, 35, 495514.

87. R. J. Gillespie and I. Hargittai, The VSEPR Model of Molecular Geometry, Prentice Hall International, London, 1991.

88. R. Gillespie and R. Nyholm, Quarterly Reviews, Chemical Society, 1957, 11, 339-380.

89. A. C. Wright, Phys. Chem. Glasses: Eur. J. Glass Sci. Technol. B, 2008, 49, 103-117.

90. N. Bansal and R. H. Doremus, Academic Press, Orlando1986, pp. 54-56.

91. O. V. Mazurin, M. V. Streltsina and T. P. Shvaiko-Shvaikovskaya, Handbook of glass data. Part A, silica glass and binary silicate glasses, Elsevier, Amsterdam, 1983.

92. S. Kohara, J. Akola, H. Morita, K. Suzuya, J. K. R. Weber, M. C. Wilding and C. J. Benmore, $P$ Natl Acad Sci USA, 2011, 108, 14780-14785.

93. S. Kohara, K. Suzuya, K. Takeuchi, C. K. Loong, M. Grimsditch, J. K. R. Weber, J. A. Tangeman and T. S. Key, Science, 2004, 303, 1649-1652.

94. S. Sen, H. Maekawa and G. N. Papatheodorou, J. Phys. Chem. B, 2009, 113, 15243-15248.

95. S. Sen and J. A. Tangeman, Am. Miner., 2008, 93, 946-949.

96. C. Larson, J. Doerr, M. Affatigato, S. Feller, D. Holland and M. E. Smith, J Phys-Condens Mat, 2006, 18, 11323-11331.

97. N. K. Nasikas, T. G. Edwards, S. Sen and G. N. Papatheodorou, J. Phys. Chem. B, 2012, 116, 2696-2702. 


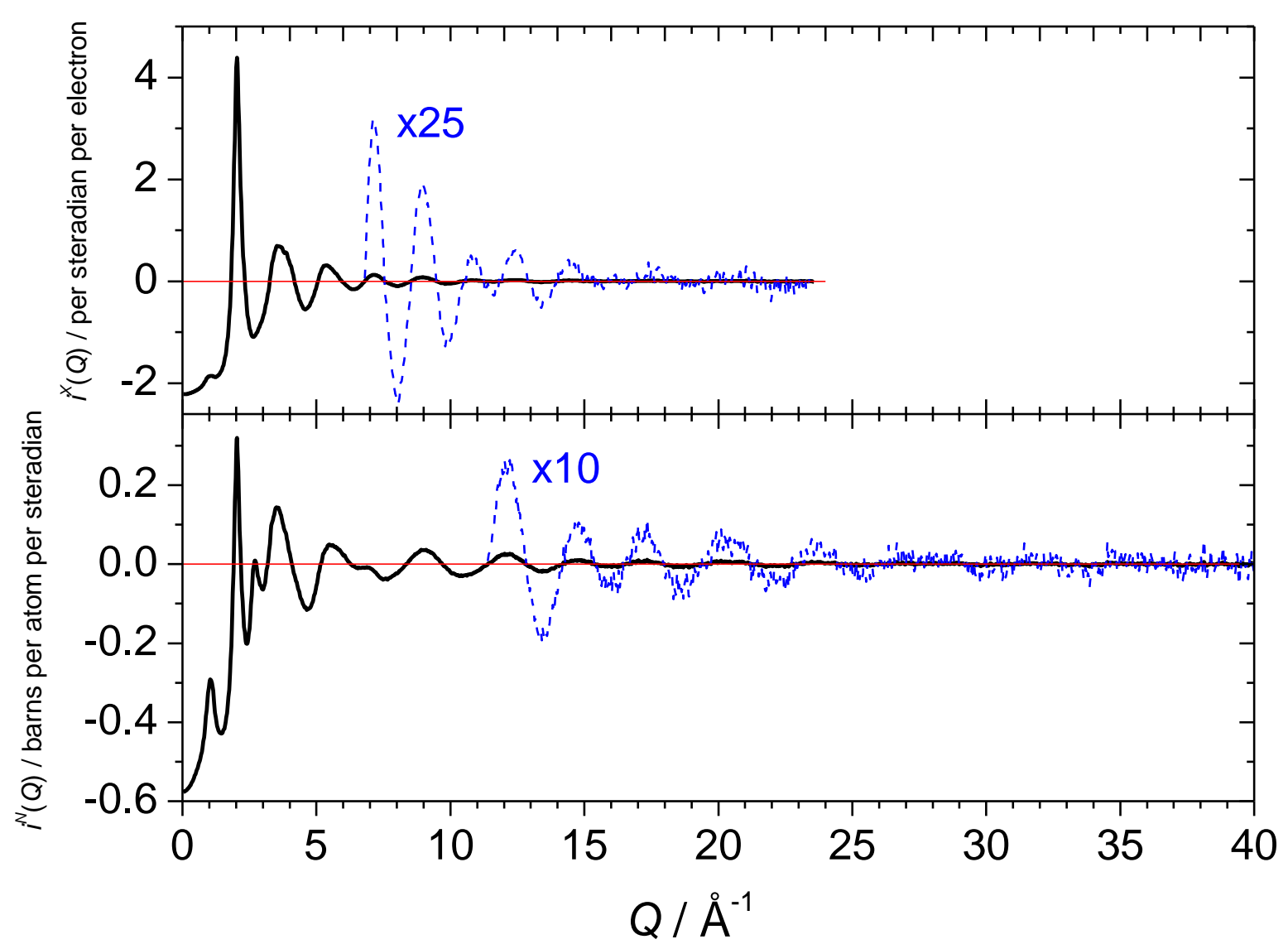

Figure 1: The x-ray and neutron distinct scattering for high lead silicate glass, $i^{X}(Q)$ and $i^{N}(Q)$ (solid lines). Dashed lines show suitable magnifications of the data in order to highlight the oscillations at high $Q$. 


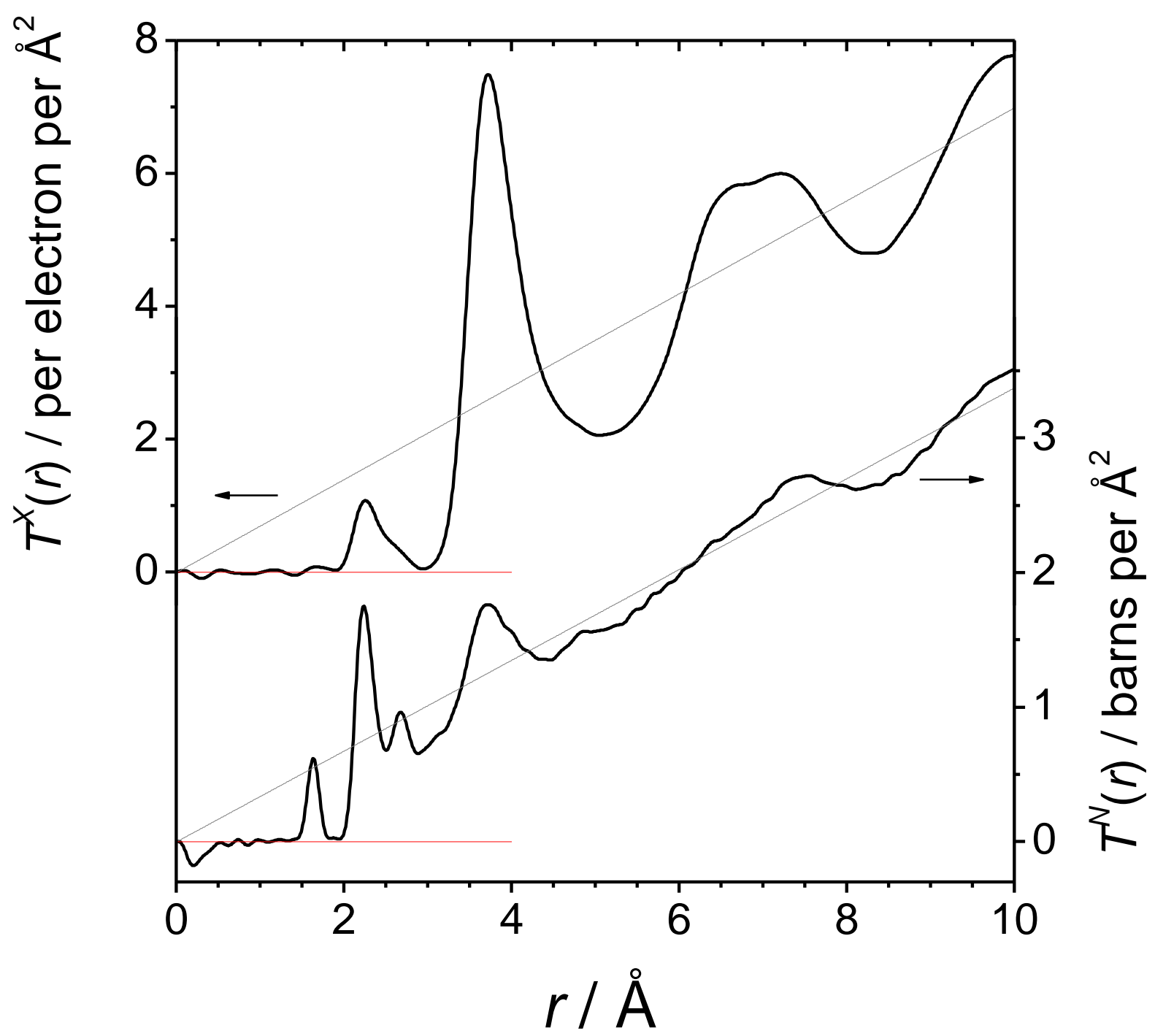

Figure 2: The x-ray and neutron correlation functions, $T^{x}(r)$ and $T^{N}(r)$, of high lead silicate glass obtained with a Lorch modification function ${ }^{77}$ and $Q_{\max }=23.62$ and $40.00 \AA^{-1}$ respectively. The average density contributions $T^{X, 0}(r)$ and $T^{N, 0}(r)$ are shown as thin lines. 


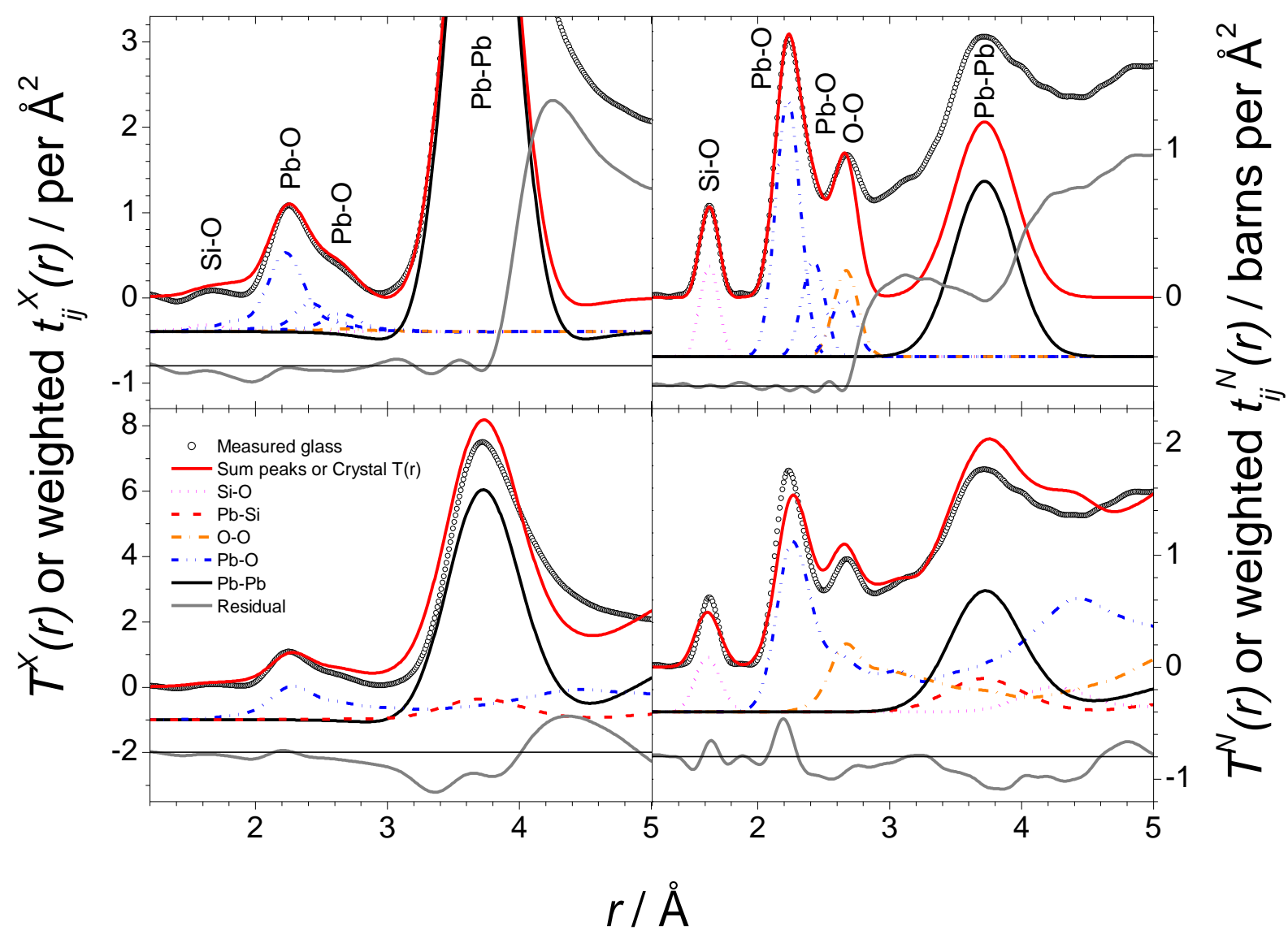

Figure 3: The $T^{R}(r)$ of Fig. 2 are shown over reduced regions of $r$ (open circles, black). Upper panels show the sum of the fitted peaks overlaid (solid line, red), with individual peaks offset below this, and residual further offset below. The lower panels show the measured $T^{R}(r)$ (open circles) together with the simulated $T^{R}(r)$ for crystalline $\mathrm{Pb}_{11} \mathrm{Si}_{3} \mathrm{O}_{17}{ }^{45}$ (solid line, red), with the appropriately weighted partial correlation functions and residual (grey) offset below, as in the upper panels. Only the $\mathrm{Pb}$ containing partials are shown in the x-ray case, and the Si-Si partial has been omitted from the neutron figure (negligibly small). See main text for details. In colour online. 


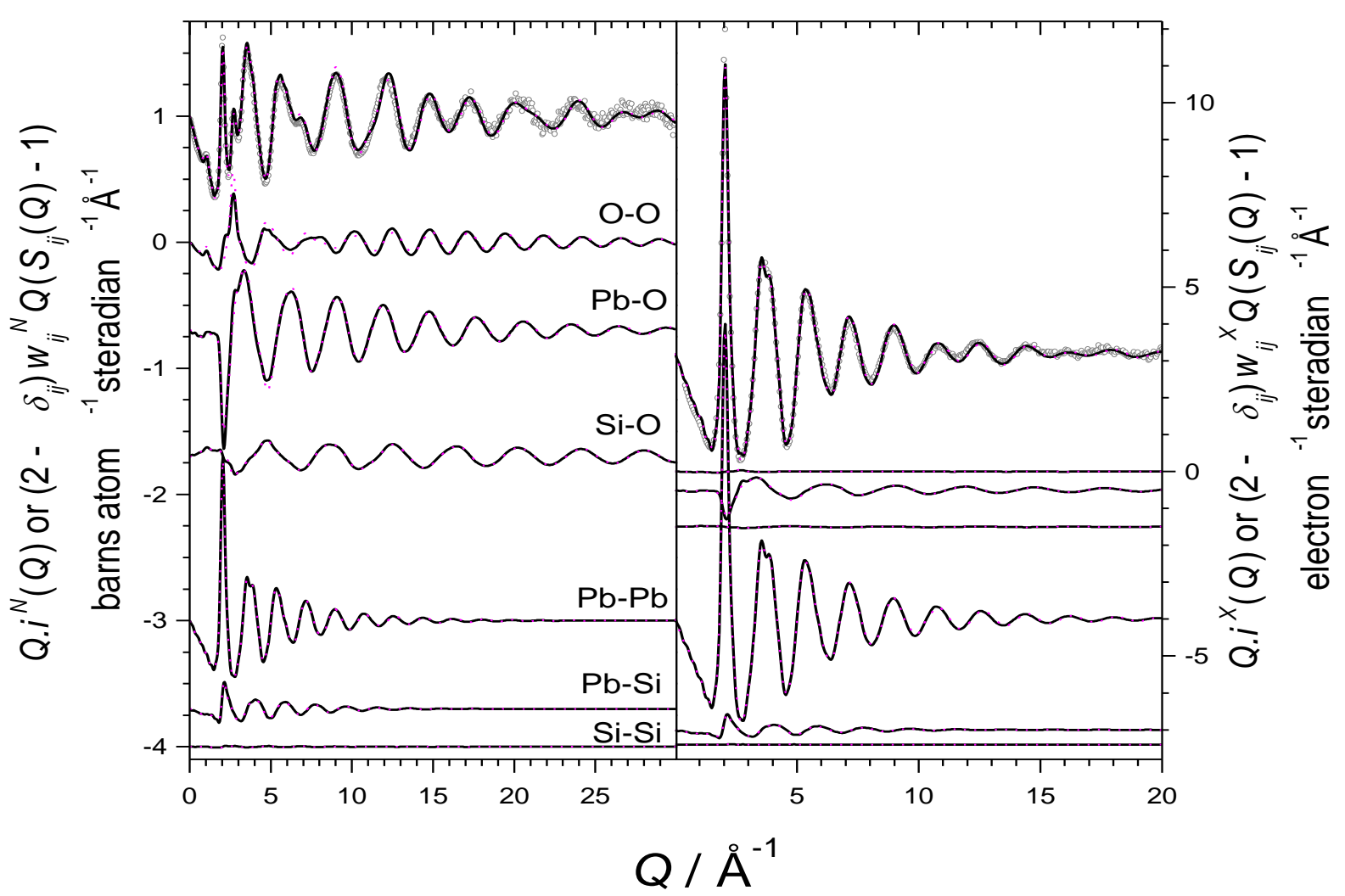

Figure 4: Interference functions measured (open circles) by neutron (left) and $\mathrm{x}$-ray (right) diffraction for the $80 \mathrm{PbO}^{2} 20 \mathrm{SiO}_{2}$ glass, compared with the model functions, ionic model: thick (black) line, lone-pair model: thin dotted (magenta) line. The appropriately weighted partial interference functions are shown vertically offset for clarity, in the same order in both panels. For clarity, the functions for the $Q^{0}$ models have been omitted, but see Fig. S4, ESI, for the weighting factor free partial interference functions for the $Q^{0}$ model. In colour online. 


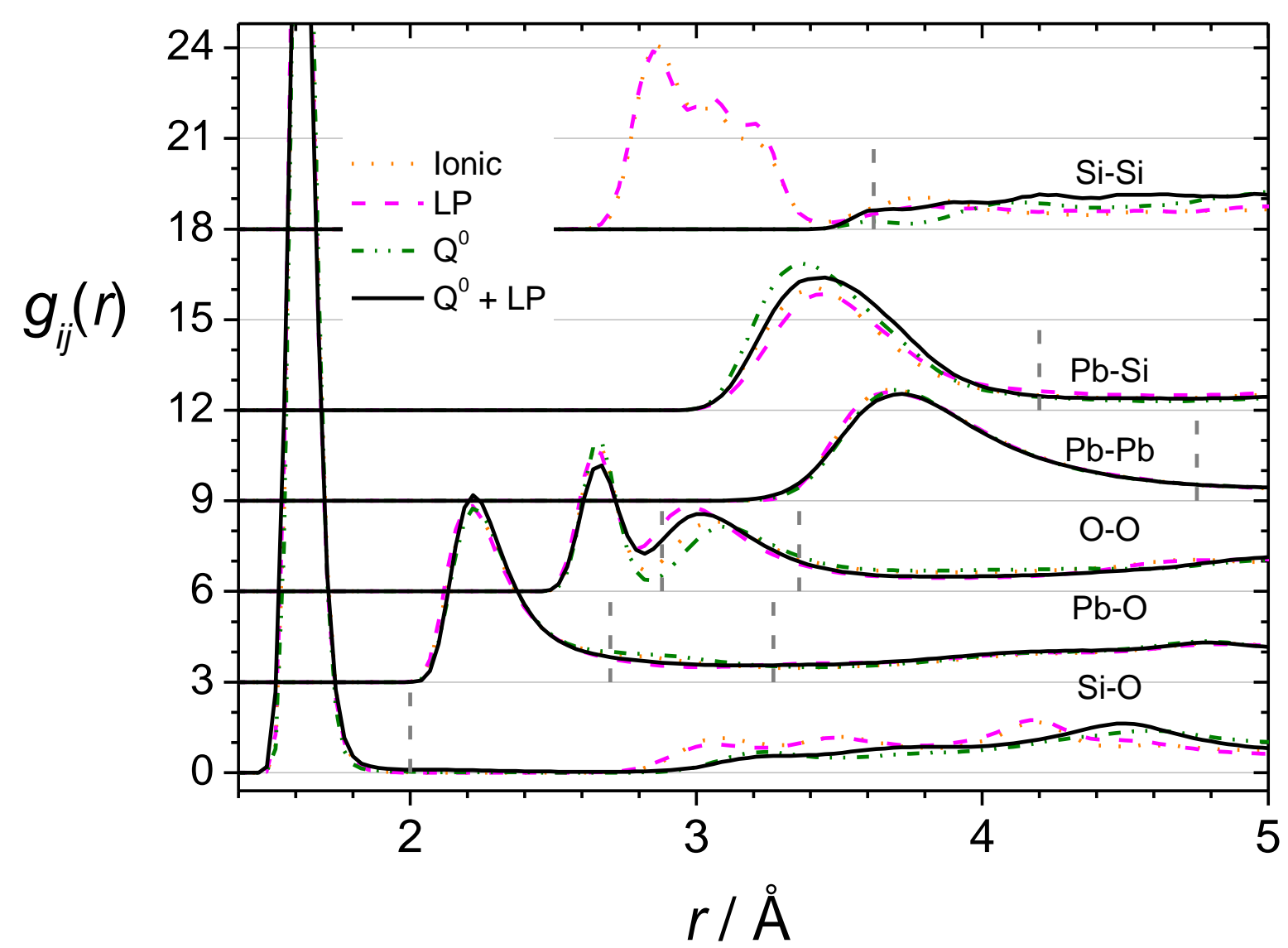

Figure 5: The partial pair correlation functions, $g_{i j}(r)$, derived from the models. Vertical offsets have been used for clarity. Vertical lines indicate cut-offs used during determination of coordination number distributions (CNDs) and bond-angle distributions (BADs). In colour online. 

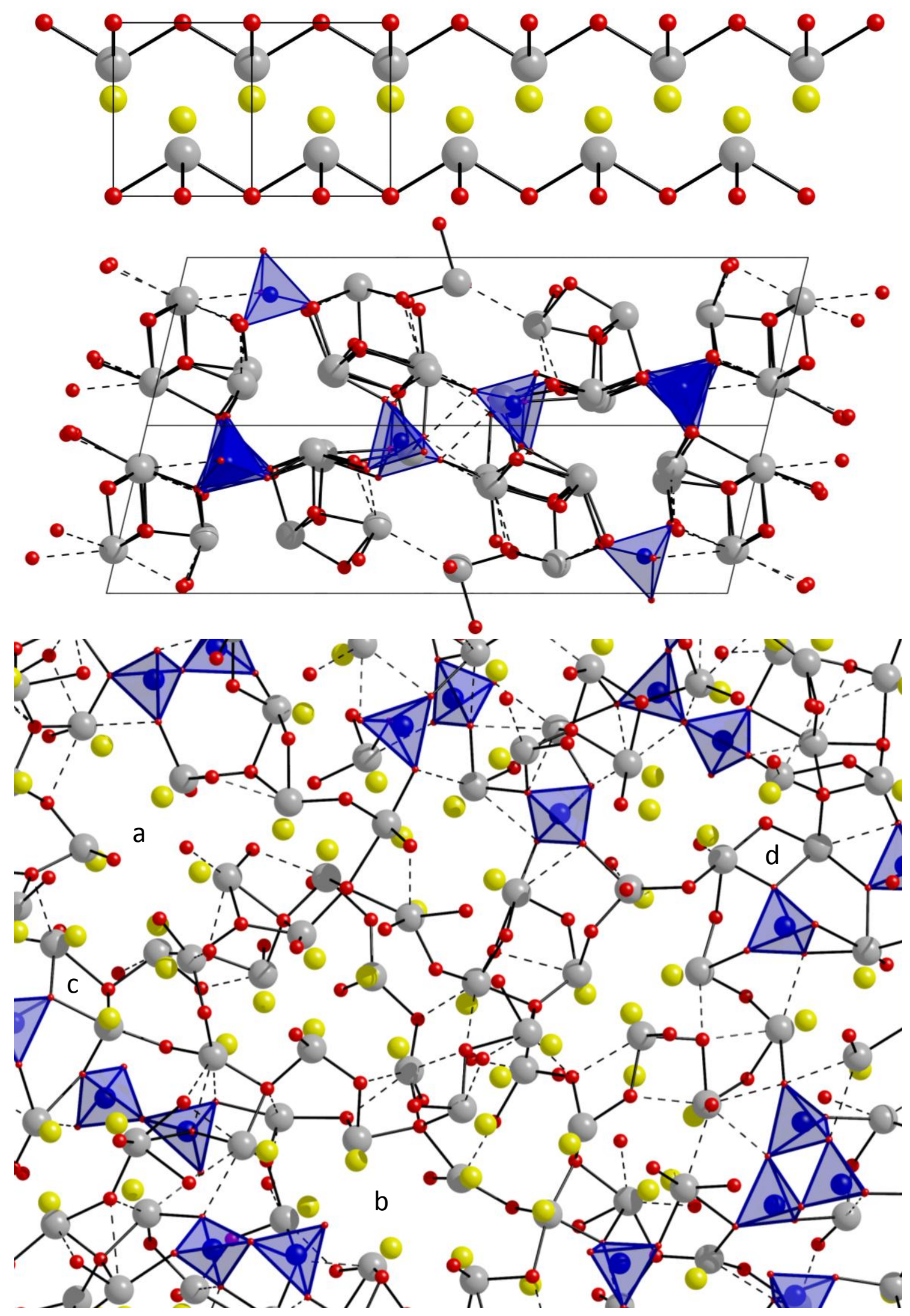

Figure 6: Top: $5 \times 1 \times 1$ supercell of $\alpha-\mathrm{PbO}^{48}$ viewed along the [010] direction. Middle: Unit cell of $\mathrm{Pb}_{11} \mathrm{Si}_{3} \mathrm{O}_{17}{ }^{45}$ viewed along the [01-1] direction. Bottom: Snapshot (approx. $31 \times 24 \AA$ ) of part of a single configuration of the lone-pair model of $80 \mathrm{PbO} .20 \mathrm{SiO}_{2}$ lead silicate glass. The region shown consists of an approximately $5 \AA$ thick slice. Silicon atoms are shown within shaded (blue) 
tetrahedra, lead atoms as large (grey) spheres, bonded to oxygen atoms (smaller spheres, red). Lone pairs are shown within $\alpha$-PbO and the glass as yellow spheres. ${ }^{66-67} \mathrm{~Pb}-\mathrm{O}$ bonds shorter than $2.7 \AA$ are shown as solid lines, whilst those between 2.7 and $3.27 \AA$ in length are dashed. The lone-pairs fill voids in the glass structure, such as those labelled $a$ and $b$. Edge sharing $\left[\mathrm{PbO}_{m}\right]$ units are in evidence, including those labelled $c$ and $d$. The cationic coordination spheres have been filled, whereas the anionic ones have not. In colour online. 


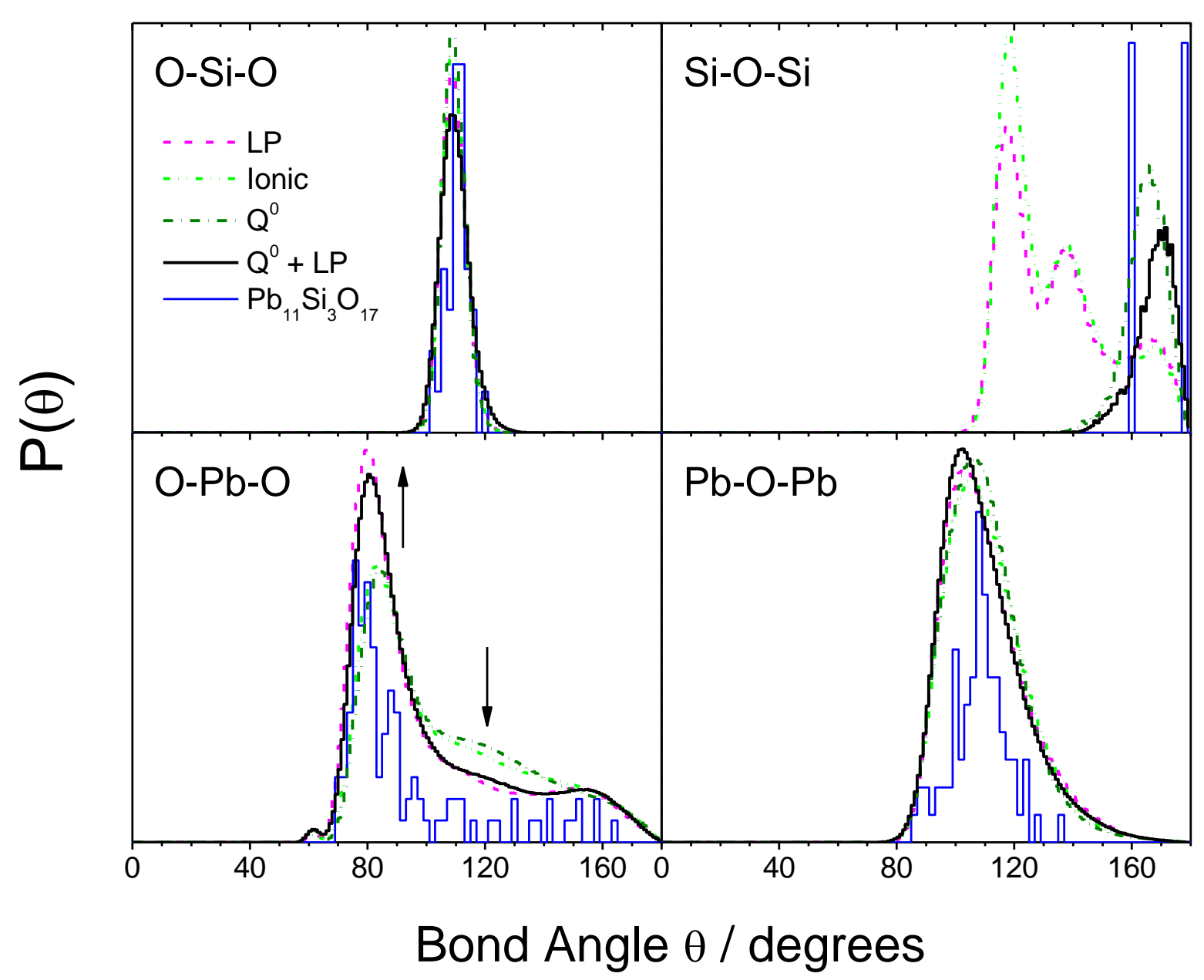

Figure 7: Bond angle histograms from the EPSR models, with $1^{\circ}$ bins. Arrows indicate the direction of change of the O-Pb-O BAD upon introduction of the LPs. The more discrete histograms (solid blue lines) correspond to the distributions in crystalline $\mathrm{Pb}_{11} \mathrm{Si}_{3} \mathrm{O}_{17},{ }^{45}$ arbitrarily scaled and with $2^{\circ}$ bins.

The same bond length cut-offs apply as in Table 5, with only the shorter $(<2.7 \AA) \mathrm{Pb}-\mathrm{O}$ bonds included. In colour online. 


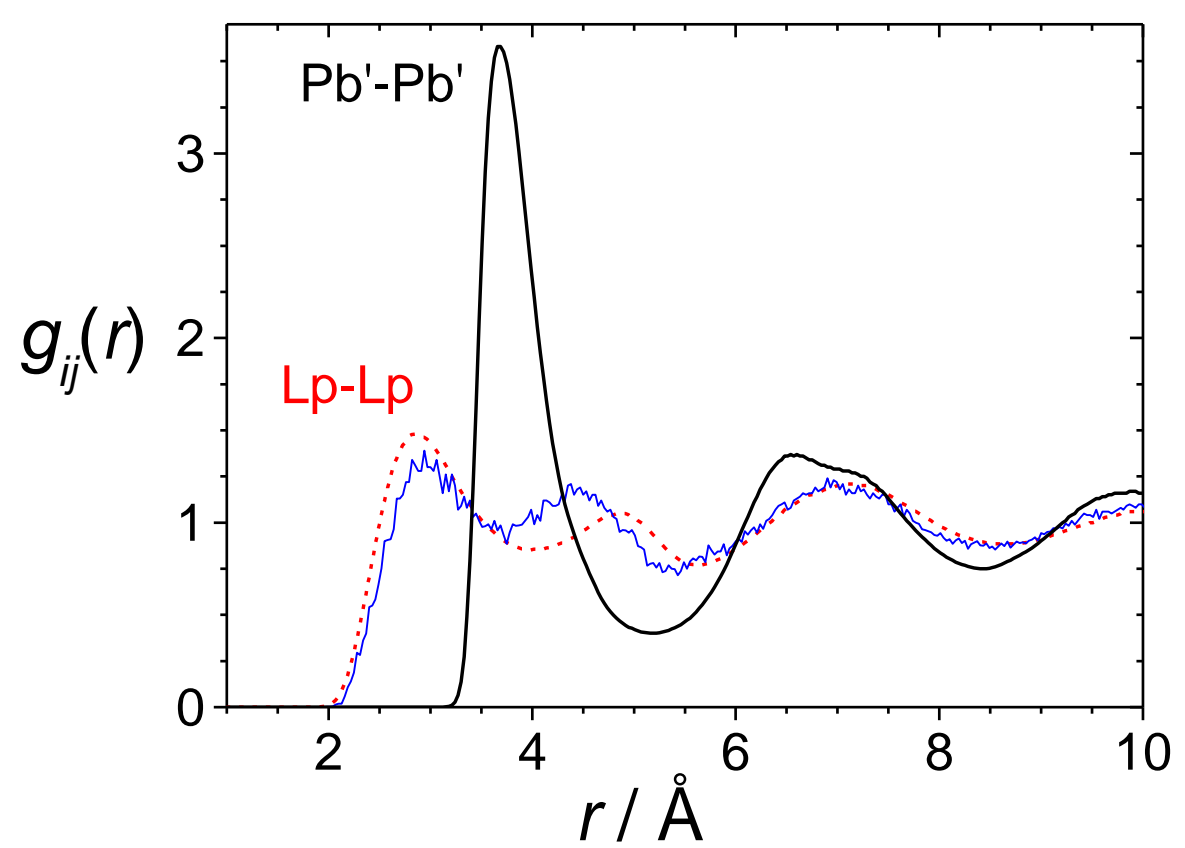

Figure 8: The partial pair correlation functions, $g_{i j}(r)$, for the $\mathrm{Pb}^{\prime}-\mathrm{Pb}^{\prime}$ and LP-LP pairs, demonstrating the net effective attractive interaction between the lone-pairs in the LP model, similar to that observed in crystalline materials, such as $\alpha$-PbO. The more noisy (solid blue) line is derived from the LP-LP distribution of a single Monte Carlo configuration, prior to perturbation by, and refinement of, the empirical potential. In colour online. 
Please cite: Phys. Chem. Chem. Phys., 2013, 15, 8506-8519

Table 1: Measured bulk properties of the high lead silicate glass, see main text for details.

\begin{tabular}{lcc}
\hline \multicolumn{1}{c}{ Property } & Value \\
\hline Mass density, $\mathrm{g} / \mathrm{cm}^{3}$ & $\rho_{m}$ & $7.95 \pm 0.05$ \\
Number density, atoms $/ \AA^{3}$ & $\rho_{0}$ & $0.05564 \pm 0.00040$ \\
Molar volume, $\mathrm{cm}^{3} / \mathrm{mol}$ & $V_{M}$ & $23.87 \pm 0.21$ \\
\hline \multicolumn{1}{c}{ Glass composition (mol\% PbO) } \\
\hline Nominal & 80.00 \\
Mass loss derived & $79.97 \pm 0.03$ \\
Density derived & $78.11 \pm 1.63$ \\
EDX analysis & $77.03 \pm 0.57$ \\
ND derived & $79.50 \pm 0.50$ \\
\hline
\end{tabular}

Table 2: Parameters defining the interatomic pair potentials used in the structure refinements. The $\mathrm{Pb}^{\prime}$ and $\mathrm{LP}$ parameters were used only in the lone-pair and $\mathrm{Q}^{0}+$ lone-pair models, see main text for details.

\begin{tabular}{lcccc}
\hline Ion & $\varepsilon, \mathrm{kJmol}^{-1}$ & $\sigma, \AA$ & $m$, (a.m.u.) & $q / e$ \\
\hline $\mathrm{Si}$ & 2.49 & 0.72 & 28 & 2 \\
$\mathrm{O}$ & 0.92 & 3.16 & 16 & -1 \\
$\mathrm{~Pb}$ & 0.60 & 2.07 & 207 & 1 \\
$\mathrm{~Pb}^{\prime}$ & 0.60 & 2.21 & 103.5 & 1.5 \\
$\mathrm{LP}$ & 0.00 & 0.00 & 103.5 & -0.5 \\
\hline
\end{tabular}


Table 3: Parameters from peak fitting to $T^{N}(r)$ and $T^{X}(r)$ measured for the 80 mol\% PbO silicate glass, see main text for details of the peak fitting procedure. Statistical errors from the fitting procedure are given in parentheses. The final column indicates whether the values are obtained from fitting $T^{N}(r)$ or $T^{x}(r)$, see text for details.

\begin{tabular}{|c|c|c|c|c|}
\hline Atom pair $i-j$ & $r_{i j}, \AA$ & $\left\langle u_{i j}^{2}\right\rangle^{1 / 2}, \AA$ & $\overline{N_{i j}}$ & Origin \\
\hline Si-O & $1.6348(23)$ & $0.050(3)$ & $3.92(14)$ & $\mathrm{N}$ \\
\hline $\mathrm{O}-\mathrm{Si}$ & & & $0.67(2)$ & $\mathrm{N}$ \\
\hline \multirow[t]{3}{*}{$\mathrm{Pb}-\mathrm{O}$} & $2.2300(3)$ & $0.0802(3)$ & $2.29(1)$ & N \\
\hline & $2.4227(10)$ & $0.071(2)$ & $0.85(1)$ & $\mathrm{N}$ \\
\hline & $2.6507(34)$ & $0.083(3)$ & $0.63(2)$ & $\mathrm{X}+\mathrm{N}$ \\
\hline Total Pb-O & & & $3.77(2)$ & $X+N$ \\
\hline Total O-Pb & & & $2.48(2)$ & $X+N$ \\
\hline $\mathrm{O}-\mathrm{O}\left[\mathrm{SiO}_{4}\right]^{*}$ & $2.6695(38)$ & $0.079(1)$ & $1.95(9)$ & $\mathrm{N}^{*}$ \\
\hline $\mathrm{Pb}-\mathrm{Pb}{ }^{+}$ & $3.7204(17)$ & $0.227(1)$ & $8.02(4)$ & $x$ \\
\hline
\end{tabular}

*Parameters fixed at those predicted from $\mathrm{Si}-\mathrm{O}$ peak area and position and assumption of tetrahedral geometry. Width fixed at that measured for vitreous silica. ${ }^{+N e g l e c t i n g}$ contributions from other terms, including $\mathrm{Pb}-\mathrm{Si}$ and $\mathrm{Pb}-\mathrm{O}$.

Table 4: Selected properties of the EPSR derived glass structure models.

\begin{tabular}{lcccc}
\hline \multirow{1}{*}{ Parameter } & Ionic & Lone-pair & $\mathrm{Q}^{0}$ & $\mathrm{Q}^{0}+\mathrm{LP}$ \\
\cline { 2 - 5 } & 1.88 & 1.95 & 1.84 & 1.82 \\
R-factor $^{63}\left(\times 10^{3}\right)$ & -540.5 & -592.2 & -541.9 & -572.6 \\
Total energy, kJmol $^{-1}$ & & & & \\
& 109.4 & 109.4 & 109.4 & 109.8 \\
Mean O-Si-O angle, $^{\circ}$ & 4.2 & 4.4 & 4.0 & 5.1 \\
RMS deviation, $^{\circ}$ & & & & \\
Mean Pb-O-Pb angle, $^{\circ}$ & 110.8 & 110.4 & 110.1 & 109.7 \\
RMS deviation, $^{\circ}$ & 13.9 & 14.4 & 13.3 & 14.2 \\
\hline
\end{tabular}


Table 5: Average coordination numbers ( $N_{i j}^{\prime}$, as defined in equation 15, ESI) and coordination number distributions (CNDs), expressed as percentages, for various atom pairs in the EPSR models of the glass, and in crystalline $\mathrm{Pb}_{11} \mathrm{Si}_{3} \mathrm{O}_{17} .{ }^{45}$ Standard deviations are shown in parentheses. The $\mathrm{Q}$ species distribution for an $80 \mathrm{PbO} .20 \mathrm{SiO}_{2}$ glass, measured by ${ }^{29} \mathrm{Si} \mathrm{MAS} \mathrm{NMR},{ }^{23}$ has been used to estimate the Si-Si and O-Si CNDs, shown for comparison. The upper cut-off radius, $r_{2}$, (equation 15,

ESI) is given in the first column. Effectively, $r_{1}=0$ in all cases. Values smaller than $0.01 \%$ are expressed as italicised zeros. A few percent of $\mathrm{Pb}$ are coordinated to seven $\mathrm{O}$ for $r_{2}=3.27 \AA$. See Fig. S7 of the ESI for a graphical representation.

\begin{tabular}{|c|c|c|c|c|c|c|c|c|c|}
\hline \multirow{2}{*}{$\begin{array}{c}\text { Atom pair } \\
\left(r_{2}, \AA\right)\end{array}$} & \multirow{2}{*}{ System } & \multicolumn{7}{|c|}{ Coordination number } & \multirow{2}{*}{ Average $N_{i}^{\prime}$} \\
\hline & & 0 & 1 & 2 & 3 & 4 & 5 & 6 & \\
\hline $\mathrm{Si}-\mathrm{O}$ & Ionic & 0 & 0 & 0 & $0.1(1)$ & $99.87(2)$ & 0 & 0 & $4.00(8)$ \\
\hline \multirow[t]{4}{*}{$(2.0)$} & Lone-pair & 0 & 0 & 0 & $0.04(10)$ & $99.9(2)$ & 0 & 0 & $4.00(6)$ \\
\hline & $Q^{0}$ & 0 & 0 & 0 & $1.0(3)$ & $99.0(3)$ & 0 & 0 & $3.99(10)$ \\
\hline & $Q^{0}+L P$ & 0 & 0 & 0 & $9.5(6)$ & $90.5(6)$ & 0 & 0 & $3.90(29)$ \\
\hline & $\mathrm{Pb}_{11} \mathrm{Si}_{3} \mathrm{O}_{17}$ & 0 & 0 & 0 & 0 & 100 & 0 & 0 & $4.00(0)$ \\
\hline $\mathrm{O}-\mathrm{Si}$ & Ionic & $44.17(1)$ & $45.09(0)$ & $10.74(4)$ & $0.03(2)$ & 0 & 0 & 0 & $0.67(66)$ \\
\hline \multirow[t]{5}{*}{$(2.0)$} & Lone-pair & $44.4(2)$ & $44.68(6)$ & $10.64(3)$ & $0.22(2)$ & 0 & 0 & 0 & $0.67(67)$ \\
\hline & $Q^{0}$ & $33.75(1)$ & $66.00(2)$ & $0.25(5)$ & 0 & 0 & 0 & 0 & $0.66(48)$ \\
\hline & $Q^{0}+L P$ & $35.43(4)$ & $64.05(7)$ & $0.52(9)$ & 0 & 0 & 0 & 0 & $0.65(49)$ \\
\hline & $\mathrm{Pb}_{11} \mathrm{Si}_{3} \mathrm{O}_{17}$ & 35.3 & 58.8 & 5.9 & 0 & 0 & 0 & 0 & $0.71(57)$ \\
\hline & ${ }^{29} \mathrm{Si}$ MAS NMR & $35(3)$ & $63(1)$ & $3(4)$ & 0 & 0 & 0 & 0 & $0.68(1)$ \\
\hline Si-Si & Ionic & $18.6(3)$ & $38.5(6)$ & $32(1)$ & $9.5(7)$ & $1.3(5)$ & $0.02(8)$ & 0 & $1.36(94)$ \\
\hline \multirow[t]{5}{*}{ (3.62) } & Lone-pair & $16.7(3)$ & $40.4(5)$ & $30.0(6)$ & $10.5(5)$ & $2.0(3)$ & $0.2(1)$ & 0 & $1.41(97)$ \\
\hline & $Q^{0}$ & $97.9(7)$ & $2.1(7)$ & 0 & 0 & 0 & 0 & 0 & $0.02(14)$ \\
\hline & $Q^{0}+L P$ & $96(1)$ & $4(1)$ & 0 & 0 & 0 & 0 & 0 & $0.04(21)$ \\
\hline & $\mathrm{Pb}_{11} \mathrm{Si}_{3} \mathrm{O}_{17}$ & 33.3 & 66.7 & 0 & 0 & 0 & 0 & 0 & $0.67(47)$ \\
\hline & ${ }^{29} \mathrm{Si}$ MAS NMR & $71(3)$ & $26(3)$ & $3(3)$ & 0 & 0 & 0 & 0 & $0.32(28)$ \\
\hline $\mathrm{Pb}-\mathrm{O}$ & Ionic & 0 & $0.3(1)$ & $6.2(5)$ & $38(1)$ & $48(1)$ & $6.9(5)$ & $0.1(1)$ & $3.55(73)$ \\
\hline \multirow[t]{4}{*}{ (2.7) } & Lone-pair & 0 & $0.04(5)$ & $4.1(4)$ & $42.9(8)$ & $44.7(9)$ & $8.1(5)$ & $0.2(1)$ & $3.57(71)$ \\
\hline & $Q^{0}$ & 0 & $0.3(1)$ & $6.7(5)$ & $39(1)$ & $48(1)$ & $6.3(5)$ & $0.1(1)$ & $3.54(73)$ \\
\hline & $Q^{0}+L P$ & 0 & $0.04(5)$ & $4.0(4)$ & $40.9(9)$ & $48(1)$ & $7.2(5)$ & $0.1(1)$ & $3.58(69)$ \\
\hline & $\mathrm{Pb}_{11} \mathrm{Si}_{3} \mathrm{O}_{17}$ & 0 & 0 & 0 & 45.5 & 45.5 & 9.1 & 0 & $3.64(64)$ \\
\hline $\mathrm{O}-\mathrm{Pb}$ & Ionic & $7.1(3)$ & $16.0(5)$ & $30.7(7)$ & $25.6(7)$ & $20.6(6)$ & $0.08(5)$ & 0 & $2.37(1.18)$ \\
\hline \multirow[t]{4}{*}{ (2.7) } & Lone-pair & $7.5(2)$ & $15.0(4)$ & $30.3(5)$ & $26.4(6)$ & $20.8(5)$ & $0.06(5)$ & 0 & $2.38(1.19)$ \\
\hline & $Q^{0}$ & $0.6(1)$ & $19.6(7)$ & $42.4(7)$ & $18.5(6)$ & $18.9(5)$ & $0.08(5)$ & 0 & $2.36(1.02)$ \\
\hline & $Q^{0}+L P$ & $1.1(1)$ & $18.0(5)$ & $41.9(5)$ & $19.0(5)$ & $20.0(4)$ & $0.07(5)$ & 0 & $2.39(1.03)$ \\
\hline & $\mathrm{Pb}_{11} \mathrm{Si}_{3} \mathrm{O}_{17}$ & 5.9 & 23.5 & 29.4 & 11.8 & 29.4 & 0 & 0 & $2.35(1.28)$ \\
\hline $\mathrm{Pb}-\mathrm{O}$ & Ionic & 0 & 0 & $0.03(4)$ & $3.8(4)$ & $34(1)$ & $41(1)$ & $17.6(9)$ & $4.84(89)$ \\
\hline \multirow[t]{4}{*}{ (3.27) } & Lone-pair & 0 & 0 & $0.29(9)$ & $10.3(5)$ & $35.4(9)$ & $35.8(9)$ & $14.9(7)$ & $4.65(98)$ \\
\hline & $Q^{0}$ & 0 & 0 & 0 & $2.6(4)$ & $28(1)$ & $41(1)$ & $22.1(7)$ & $5.00(93)$ \\
\hline & $Q^{0}+L P$ & 0 & 0 & $0.15(6)$ & $6.9(4)$ & $34.3(7)$ & $37.3(9)$ & 22.7 & $4.77(97)$ \\
\hline & $\mathrm{Pb}_{11} \mathrm{Si}_{3} \mathrm{O}_{17}$ & 0 & 0 & 0 & 4.5 & 27.3 & 45.5 & 22.7 & $4.86(81)$ \\
\hline $\mathrm{O}-\mathrm{Pb}$ & Ionic & $1.5(1)$ & $6.2(3)$ & $16.8(8)$ & $28.3(7)$ & $39.3(6)$ & $6.7(5)$ & $1.0(2)$ & $3.22(1.12)$ \\
\hline \multirow[t]{4}{*}{ (3.27) } & Lone-pair & $2.4(2)$ & $6.2(3)$ & $19.9(5)$ & $29.2(6)$ & $36.0(5)$ & $5.7(3)$ & $0.7(1)$ & $3.10(1.14)$ \\
\hline & $Q^{0}$ & 0 & $0.8(1)$ & $16.8(6)$ & $39.9(6)$ & $34.2(5)$ & $7.2(4)$ & $1.1(2)$ & $3.34(90)$ \\
\hline & $Q^{0}+L P$ & $0.18(5)$ & $1.8(2)$ & $23.9(5)$ & $35.3(6)$ & $32.5(5)$ & $5.7(3)$ & $0.7(1)$ & $3.18(95)$ \\
\hline & $\mathrm{Pb}_{11} \mathrm{Si}_{3} \mathrm{O}_{17}$ & 2.9 & 2.9 & 11.8 & 41.2 & 41.2 & 0 & 0 & $3.15(94)$ \\
\hline
\end{tabular}


Table 6: Values obtained by fitting of Lorentzian lineshapes to the FSDPs of the x-ray and neutron distinct scattering functions, and to the pre-peak of the neutron distinct scattering function.

Equivalent parameters for vitreous $\mathrm{SiO}_{2}$ based on the $Q$ and $\Delta Q$ obtained by Wright ${ }^{89}$ are shown for comparison.

\begin{tabular}{cccccc}
\hline $\begin{array}{c}\text { Peak } \\
\text { position }\end{array}$ & $\begin{array}{c}\text { Peak } \\
\text { width }\end{array}$ & $\begin{array}{c}\text { Periodicity } \\
2 \pi / Q, \AA\end{array}$ & $\begin{array}{c}\text { Correlation } \\
\text { Length } \\
2 \pi / \Delta Q, \AA\end{array}$ & $\begin{array}{c}\text { Number } \\
\text { of periods } \\
Q / \Delta Q\end{array}$ & Assignment \\
\hline $2.04(1)$ & $0.32(1)$ & $3.08(2)$ & $19.6(6)$ & $6.4(2)$ & Interlayer $\mathrm{Pb}-\mathrm{Pb}$ \\
$1.06(1)$ & $0.56(1)$ & $5.94(6)$ & $11.3(2)$ & $1.90(4)$ & Dilute silicate anions \\
$1.53(2)$ & $0.63(2)$ & $4.11(5)$ & $10.0(3)$ & $2.43(8)$ & Network cages in $\mathrm{SiO}_{2}$ \\
\hline
\end{tabular}

